\title{
MAPOCHO INCAICO SUR: EL TAWANTINSUYU ENTRE EL RÍO MAIPO Y EL CORDÓN DE ANGOSTURA
}

\author{
INCA OF SOUTHERN MAPOCHO: THE TAWANTINSUYU BETWEEN \\ MAIPO RIVER AND THE ANGOSTURA MOUNTAIN RANGE
}

\author{
Rubén Stehberga, Gonzalo Osoriob \& Juan Carlos Cerda ${ }^{C}$
}

Se proporcionan los resultados de los análisis históricos y arqueológicos de la ocupación indígena entre la ribera sur del río Maipo y el cordón de Angostura durante el Tawantinsuyu. Se identifica el camino inca principal o Qhapaq Nan y el camino real a los promaucaes, ambos de origen prehispánico. Se definen seis distritos poblacionales. Los emplazados más al norte destacan por la presencia de grandes acequias; aquellos cercanos al cordón de Angostura presentan construcciones arquitectónicas en la cima de cerros y una mayor sacralización del paisaje. El artículo sintetiza lo que constituyó la ocupación humana de la parte meridional de la provincia incaica del Mapocho.

Palabras clave: Mapocho, Maipo, Inca, Tawantinsuyu, Qhapaq Ñan, etnohistoria.

This paper presents the results obtained from the historical and archaeological analyses of the indigenous occupation between the southern bank of the Maipo valley and the Angostura mountain range during the Tawantinsuyu period. The main Inca trail, or Qhapaq Nan, and the Inca royal road to the promaucaes, both of pre-Hispanic origin, are identified. Six population districts are defined. The districts located further north and closest to the Maipo river stand out for the presence of large ditches, while those located further south, adjacent to the Angostura mountain range, show defensive systems and a greater sacralization of the landscape. The article summarizes the current evidence on the human occupation of the southern part of the Inca Province of Mapocho.

Keywords: Mapocho valley, Maipo valley, Inca, Tawantinsuyu, Qhapaq Nan, ethnohistory.

\section{INTRODUCCIÓN}

A partir de información documental y evidencia arqueológica se ha propuesto la existencia de la provincia incaica del Mapocho, la cual habría abarcado un espacio de $104 \mathrm{~km}$, comprendido entre el cordón transversal de Chacabuco por el norte y el cordón transversal de Angostura por el sur (Sotomayor et al. 2016). Estos límites habrían permitido al Tawantinsuyu controlar los principales pasos camineros longitudinales de la zona y, por tanto, los desplazamientos de personas y mercancías entre el mundo indígena del sur de Chile (araucanos) y las poblaciones del norte de Chile y centro oeste argentino. Asimismo, habrían posibilitado la introducción de una gigantesca red de canales que incorporaron miles de hectáreas, anteriormente improductivas, a la agricultura excedentaria (Stehberg et al. 2021).

Es notoria la coincidencia espacial de la provincia incaica del Mapocho con la parte principal del territorio de la cultura Aconcagua, ${ }^{1}$ cuyos habitantes ocupaban los valles del Mapocho y del Maipo en el momento inmediatamente anterior a la expansión del Tawantinsuyu a Chile central. Las investigaciones científicas muestran que los habitantes de esta cultura vivieron cerca de cursos

A Rubén Stehberg, Sociedad Chilena de Arqueología. orcid: 0000-003-2276-846X. E-mail: Stehberg.ruben@gmail.com

B Gonzalo Osorio, Facultad de Medicina de la Universidad de Chile. ORCID: 0000-0001-5678-7787.

E-mail: carlososorio@uchile.cl

C Juan Carlos Cerda, I. Municipalidad de San Felipe. ORCID: 0000-0002-7858-1680. E-mail: cerda.juan@gmail.com 
de agua -esteros, vertientes, ríos y napas freáticas altas-, subsistiendo de la cacería de guanacos, la recolección de frutos y plantas silvestres, los recursos marinos estacionales y las prácticas hortícolas, estas últimas regadas con el agua que tenían cerca. Entre uno y otro asentamiento humano se generaban amplios espacios desérticos e improductivos (Sanhueza et al. 2007; Falabella et al. 2016).

En otro artículo (Stehberg et al. 2021) hemos sugerido que el incremento poblacional ejerció presión por una mayor cantidad de alimentos, para lo cual fue necesario extender las áreas agrícolas. Para ello era preciso construir canales y acequias, pero la población local no contaba con el conocimiento técnico necesario y las autoridades no tenían el poder para congregar un número suficiente de trabajadores. En esos momentos el Tawantinsuyu se encontraba en una fase expansiva y disponía de los más avanzados conocimientos hidroagrícolas, amén de una notable capacidad para movilizar y organizar grandes contingentes humanos. A partir del interés del Inca de controlar nuevas poblaciones, incluyendo el recurso de agua, y del interés de los habitantes del Mapocho y del Maipo de extender sus campos agrícolas, los acuerdos no se hicieron esperar. Bajo la nueva administración del Tawantinsuyu -con presencia de mitimaes especialistas traídos de más al norte y con la participación de mano de obra local- los valles del Mapocho y del Maipo experimentaron una notable transformación aproximadamente a partir del año 1400. Se edificaron bocatomas y se construyeron 15 grandes canales en el río Mapocho e igual número en el río Maipo, incorporándose a la agricultura miles de tierras anteriormente improductivas, principalmente para el cultivo de maíz. El paisaje fue resacralizado mediante la construcción de adoratorios de altura (cerro El Plomo, Lo Barnechea 23, cerro Peladeros, cerro Bismarck), introducción de wakas o lugares sagrados (cerro Chena, Ruinas de Chada, Casa del Viento o waira vasi, Infiernillo) e introducción de topónimos quechuas (guaca, Apoquindo, Ingalongo, estero del Inga).

La población local reforzó su culto anterior al Sol, ahora elevado a divinidad principal, dominó el quechua, introdujo nuevos motivos decorativos en su cerámica, aprendió a vivir en chacras y cambió su forma tradicional de enterratorio. ${ }^{2}$ Las antiguas jefaturas fueron reemplazadas por señores agrícolas con capacidad para producir, almacenar e intercambiar excedentes. Estos descendientes de la cultura Aconcagua fueron denominados en el siglo XVI como mapochoes (Medina 1897: 366), ${ }^{3}$ nombre que debiera ser rescatado para designar a los habitantes originarios de estos valles, antepasados de muchas familias mestizas de Chile central. Un ejemplo de ello fue doña Elvira, hija del cacique de Talagante, quien se casó con el conquistador español Blumenthal, dando origen a la familia Flores y a una extensa descendencia que llega hasta el presente. Es posible que su hija, doña Agueda Flores, fuera, por lejos, la mujer más rica de Chile durante el siglo Xvi, y entre sus sucesoras estuvo la célebre Quintrala.

Un artículo inicial denominado "Mapocho incaico" (Stehberg \& Sotomayor 2012) demostró la existencia de una ocupación incaica fuerte en el valle del Mapocho, con presencia de un centro administrativo y ceremonial principal en el sector de la Plaza de Armas de Santiago. Dicho centro estuvo dirigido en la década de 1530 y principios de la siguiente por el gobernador Quilicanta, orejón perteneciente a la panaca real del Cuzco. Esta autoridad recibió la expedición castellana de Diego de Almagro en 1536 y la de Pedro de Valdivia en 1540, brindándoles apoyo. Este último fundó la ciudad de Santiago en febrero de 1541 sobre el centro administrativo y ceremonial inca del Mapocho (actual Plaza de Armas). Su pareja, doña Inés de Suárez, dio muerte al mencionado gobernador durante la sublevación indígena del 11 de septiembre de 1541, acusándolo de conspiración. Este acto puso drástico fin a la ocupación del Tawantinsuyu en la zona, la que había logrado mantenerse activa por ocho años tras la caída del Tawantinsuyu en los Andes centrales. Los mapochoes fueron entregados en encomienda a los conquistadores españoles, algunos lograron sobrevivir e incluso prosperar en los años que siguieron, cultivando las chacras de sus amos (origen del campesinado chileno) y obteniendo la sexta parte del oro que lograran obtener en el trabajo minero (sesmos de oro de la Tasa de Santillán), con la cual pudieron comprar ganado para sus comunidades. Es interesante notar que, al ver que algunos indígenas se enriquecían, los encomenderos introdujeron los "censos", que eran préstamos obligatorios del dinero de las comunidades a los europeos, los cuales, obviamente, nunca se devolvieron. Pero esta es otra historia (Jara 1961; León 2017).

Durante la profundización de las investigaciones de la provincia incaica del Mapocho y habida cuenta de la gran cantidad de información existente, se consideró, metodológicamente, que era conveniente subdividirla en tres partes: norte, central y sur. Habiéndose completado los estudios de las primeras dos, este artículo da cuenta de los resultados obtenidos en el análisis de la parte sur, con lo cual se pone término a lo que originalmente nos 
habíamos propuesto realizar junto con el historiador Gonzalo Sotomayor (Q. E. P. D.).

En esta ocasión se ha organizado la información en distritos poblacionales indígenas para visualizar los lugares de mayor concentración de habitantes y, eventualmente, distinguir aquellos donde la influencia del Tawantinsuyu fue mayor.

\section{MATERIALES Y MÉTODOS}

Desde los inicios de esta línea de investigación, el año 2011, se ha implementado una metodología consistente en el trabajo interdisciplinario de un historiador, un arqueólogo y un geógrafo, todos enfocados en la tarea de reunir la mayor cantidad de información relativa al mundo aborigen durante el Período Tawantinsuyu, así como a su aprovechamiento por parte de los conquistadores castellanos y su sobrevivencia durante el siglo XVI y comienzos del xvir. En todos los casos, la perspectiva utilizada fue zonal, abarcando un amplio espacio correspondiente a un valle completo o parte importante de este. En esta oportunidad, el área seleccionada quedó comprendida entre el río Maipo por el norte y el cordón de Angostura de Paine, por el sur. Esta delimitación dejó fuera importantes sitios incaicos como el pucará de Chena, por encontrarse al norte del área de estudio.

Cabe mencionar que las interpretaciones, la construcción de modelos y las conclusiones obtenidas se basaron, hasta donde fue posible, en la evidencia empírica y los datos recopilados, lo cual implica que los resultados son válidos únicamente para el área analizada.

El historiador centró su esfuerzo en la búsqueda de nuevos datos en archivos documentales públicos y privados existentes en la ciudad de Santiago. Para este artículo los trabajos se concentraron, principalmente, en los fondos Escribanos de Santiago (Es) y Real Audiencia (RA), ambos en el Archivo Nacional Histórico (ANH), y en el Fondo Hospital Nuestra Señora del Socorro (FHNss), Museo Nacional de Medicina (MNM), Santiago. Por su parte, el arqueólogo recopiló la información etnohistórica editada existente y realizó el trabajo de integración e interpretación de los datos y la redacción del artículo. El geógrafo procesó la información utilizando el Sistema de Información Geográfica, construyendo mapas temáticos a partir de los antecedentes recopilados relativos a toponimia indígena, propietarios europeos, pueblos de indios y redes viales.
Dada la naturaleza de los documentos utilizados, donde las referencias a topónimos, localización de las propiedades, deslindes y elementos del paisaje son bastante vagas, su localización en los mapas puede ser, en algunos casos, bastante imprecisa. En este manuscrito, los pasajes de las citas destacados en cursiva son nuestros.

En este artículo se introduce el concepto de distrito, siguiendo en parte la definición de la Real Academia Española (2019): "Cada una de las demarcaciones en que se subdivide un territorio o una población para distribuir y ordenar el ejercicio de los derechos civiles y políticos, o de las funciones públicas, o de los servicios administrativos". Este concepto de desarrollo territorial resulta operativo en el contexto de la relación centroperiferia que se habría establecido al interior de la provincia incaica del Mapocho.

Finalmente, se han incorporado las correcciones sugeridas por los evaluadores, las cuales han enriquecido significativamente el artículo.

\section{RESULTADOS}

$\mathrm{Al}$ analizar los mapas temáticos del área comprendida entre el río Maipo y el cordón transversal de Angostura de Paine (Mapocho incaico sur), se observa que el espacio está cruzado por una serie de caminos longitudinales y algunos distritos de ocupación humana vinculados a dichos caminos, todos los cuales tienen claro origen tardío prehispánico, pero que fueron aprovechados por los castellanos y sus descendientes apenas conquistaron este territorio a fines de 1540. Describiremos a continuación esta infraestructura, proporcionando los antecedentes documentales y arqueológicos utilizados.

\section{Caminos longitudinales}

Se distinguen el Camino del Inca principal o Qhapaq Ñan, que corría por la falda de la cordillera de los Andes, y el camino real a los promaucaes que circulaba paralelamente unos kilómetros más al poniente, pasando por el vado del Maipo.

\section{Camino Inca principal o Qhapaq Ñan}

Sabemos que el Camino del Inca cruzó el río Maipo por una temprana referencia del cronista Gerónimo de Vivar, en la cual relata que, a mediados de 1543, Pedro 


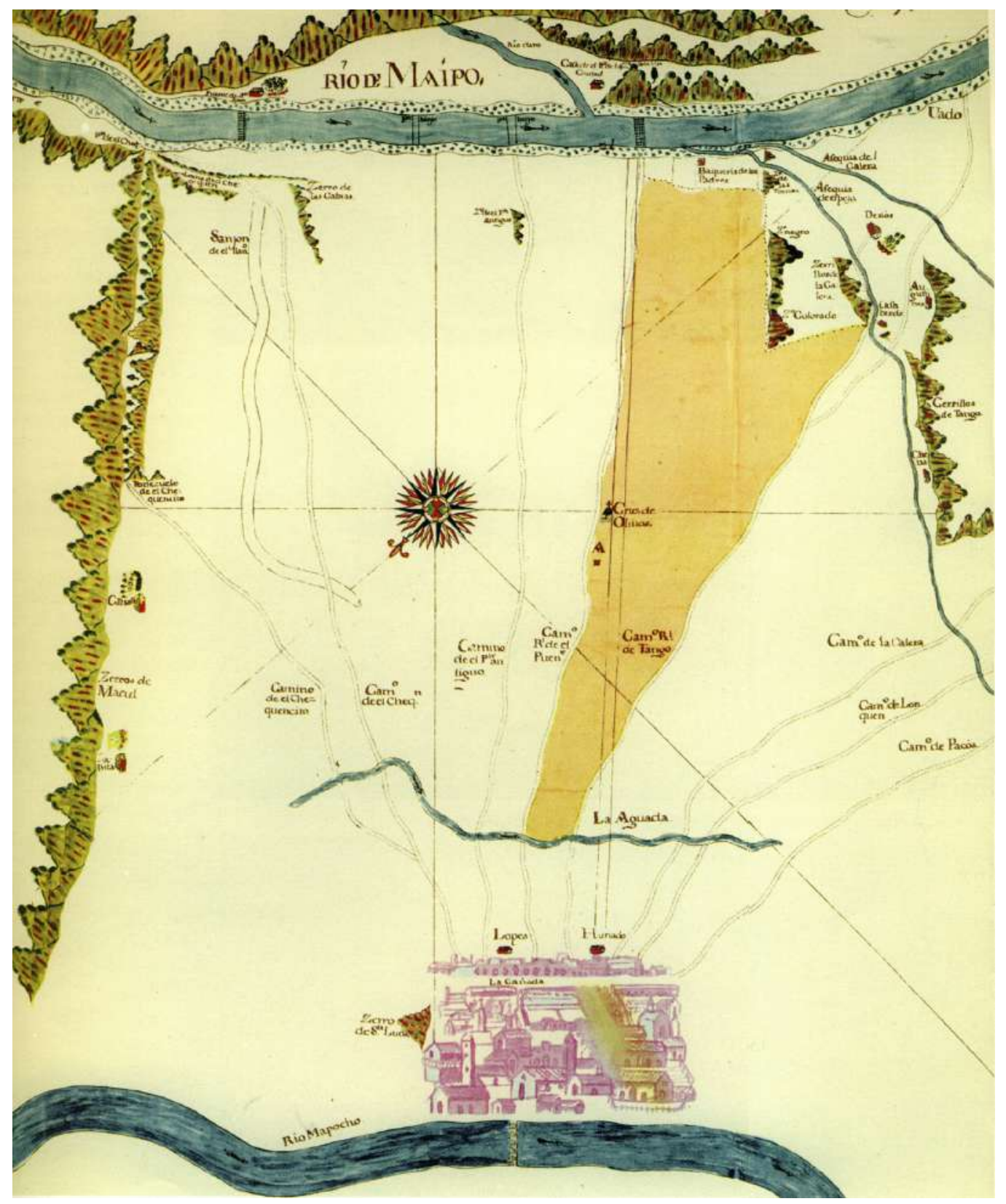

Figura 1. Plano del Llano del Maipo (aproximadamente 1755-1761) de Antonio Lozada, que muestra los caminos que salían de Santiago en dirección al río Maipo. Figure 1. Plan of the Maipo Plains (around 1755-1761) by Antonio Lozada, showing the roads leaving Santiago toward the Maipo river.

de Valdivia cabalgó con veinte de a caballo por las riberas de este río y "halló un sitio donde los Incas hicieron una puente cuando vinieron a conquistar esta tierra y estaba el sitio arruinado. Fue más adelante y halló sitio y lugar oportuno" (Vivar 1979 [1558]). Con respecto a la localización de este puente, varios antece- dentes lo sitúan en las inmediaciones de la confluencia del río Claro con el Maipo. El Plano del Llano del Maipo (aproximadamente entre 1755-1761), de Antonio Lozada (Instituto Geográfico Militar 1981), muestra ocho caminos que salían de Santiago hacia el río Maipo (fig. 1). El tercero de oriente a poniente corres- 


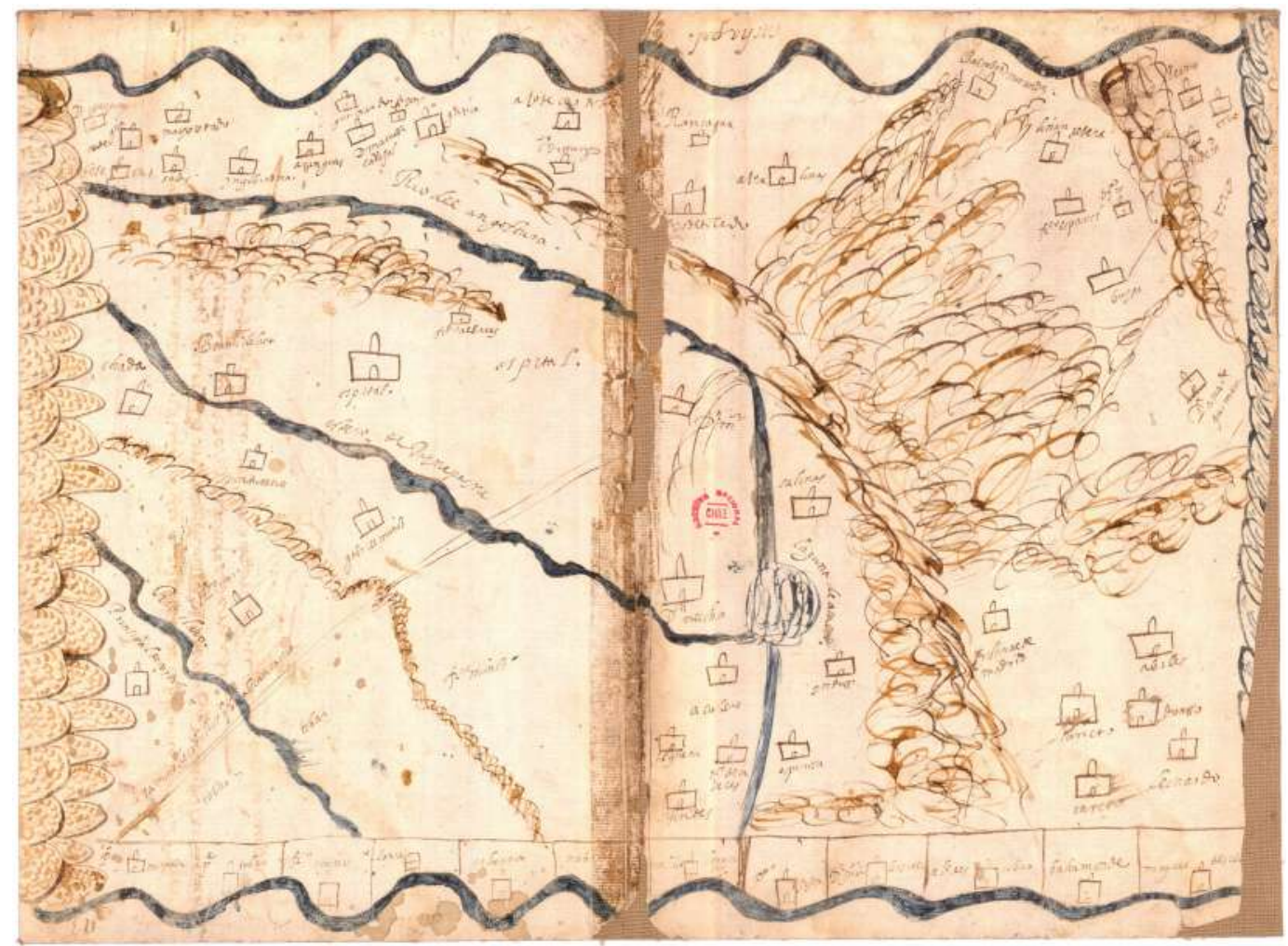

Figura 2. Región entre el Maipo y el Cachapoal, partido de Rancagua, 1617. El mapa muestra el camino que unió Pirque y El Principal con Angostura y Aculeo (línea curva que cruza diagonalmente el plano). Figure 2. Region between the Maipo and the Cachapoal, district of Rancagua, 1617. The map shows the road that joined Pirque and El Principal with Angostura and Aculeo (curved line crossing diagonally the map).

pondió al "Camino del P[uen]te Antiguo", que probablemente empalmaba con la actual calle Carmen o una paralela hacia el oriente que ha desaparecido, para cruzar el río Maipo inmediatamente al poniente del cerro Isla de las Cabras y un poco más arriba de la desembocadura del río Claro, continuando rumbo sur en dirección a Pirque y Chada. El puente se representó por dos líneas paralelas y tenía escrito "puente biejo". De acuerdo con Cabeza y Tudela (1985), este puente se encontraba a los $33^{\circ} 40^{\prime} \mathrm{S}$ y $70^{\circ} 35^{\prime} \mathrm{O}$, aproximadamente. ${ }^{4}$

Respecto de su continuación hacia el sur, Odone (1997: 194) señala que:

[...] los espacios comprendidos entre el río Maipo por el norte y el valle de Chada por el sur se encontraban conectados mediante el trazado de una serie de caminos. Por una parte, el camino 'real de la Angostura' o 'Camino que iba a los Promaucaes'. Por otra, el camino del 'ataxo portezuelo casas del inga', que permitía la comunicación con la zona del Principal de Córdoba con 'jaguei' (Alto Jahuel) y, por último, el sendero del 'portezuelo viejo' que seguía a estero del Inca y Chada.
A esta red de senderos hay que agregar el "Camino de caballos q' ba a Rancagua” marcado con una gruesa línea en el mapa de Pirque del año 1617 (Cabeza \& Tudela 1985: 25). Aunque el mapa es algo tardío y no proporciona información acerca de su origen prehispánico, el camino unió Pirque y El Principal con Angostura y Aculeo, ambos sectores con importantes asentamientos incaicos del sur del Maipo, lo que lleva a considerar la posibilidad de un origen prehispánico. El mapa de la región entre los ríos Maipo y Cachapoal de 1617 (RA, vol. 2845) muestra este camino como una línea curva que cruza diagonalmente el plano. El parche central vertical cubre parcialmente el camino real a los promaucaes (fig. 2). Ese mapa no muestra el camino incaico y su prolongación hacia el portezuelo de Chada.

A continuación, se proporcionan seis referencias históricas a estos caminos extraídas de Odone (1997: 194). Una posesión de tierras del valle del Maipo se 
refiere a "la parte que llaman del Portezuelo Cassas del Inga" (RA, vol. 409, años 1663-1665, f. 9r). Otro documento señala: "que el capitán don Antonio Chacón y Quiroga tuvo en las tierras de la otra banda de Maypo y paraxe del Portezuelo del camino del ataxo que ba a la Angostura y Aculeo majadas y corrales" (RA, vol. 409, pieza 1, años 1663-1665, fs. 2v-3r). Un pleito de Antonio Chacón y Antonio Jaraquemada especifica: "en la parte que llaman portezuelo cassas del Inga" (RA, vol. 409, años 1663-1665, f. 9v). Asimismo, "dixo que el portezuelo que esta enfrente del principal camino real" (RA, vol. 409 , pieza 1 , años $1663-1665$, f. 6v) o cuando señala: "[...] adelante del dicho portesuelo y un jaguei de agua questa frontero a tres serrillos del dicho portezuelo asia la Angostura" (RA, vol. 409, pieza 1, años 1663-1665, f. 8v). Los portezuelos y las angosturas que se mencionan corresponden probablemente al portezuelo de Chada. "Jaguei" en mapuzungun es poza o charco, topónimo que pudo derivar en Jahuel (actual Alto Jahuel), en la hacienda de Antonio Chacón.

Con respecto al "sendero antiguo del Principal de Córdoba a Chada por Quebrada del Inca" y su origen prehispánico valga la cita:

[...] bajando el portezuelo que oy se uza para la Angostura por donde ba el camino que ba a la puente de maypo a la mano derecha fuera del dicho camino y de otro antiguo que llaman del Portesuelo biejo quedando ambos caminos a la mano ysquierda yendo de esta ciudad (RA, vol. 409, pieza 1, años 1663-1665: f. 14).

A la continuación de este hacia el portezuelo y cuesta de Chada parece referirse el siguiente documento. El título de merced de tierras del Principal de Maipo y Rancagua dado a Alonso de Córdoba el Mozo, el 1 de agosto de 1579, indica que requirió que se

[...] le hiciesse merced de las tierras que son desde el corral de las yeguas y el tambo que corra derecho hasta ciento y cincuenta quadras de cabesadas y de largo hasta el camino real de la questa de cómo ban a lo del hospital. ${ }^{5}$

La cita se está refiriendo posiblemente al tambo de El Principal de Pirque y al camino real de la cuesta de Chada. Además, conviene recordar que la primera hacienda del Hospital (San Juan de Dios) estuvo cerca de Chada, alrededor del año 1591, y que, posteriormente, fue permutada por otra más al poniente, donde se localiza actualmente. Un descendiente de Alonso de Córdoba declaró en 1664 que sus tierras corrían "desde el río Claro para Chada” (Izquierdo 1982: 85).

Subsisten varios problemas con respecto a este tramo del Camino del Inca (fig. 3). Hasta la fecha no se han hallado vestigios físicos del mismo, motivo por el cual su presencia deriva del supuesto de que, habiendo un portezuelo en Chada que separaba dos sitios incaicos tan importantes como lo fueron las Ruinas de Chada y el Cerro Grande de La Compañía, debió existir necesariamente un camino que los comunicara. Asimismo, la lógica expansiva incaica suponía la habilitación de senderos de penetración hacia nuevos territorios, los cuales superaban usualmente los cordones montañosos por los principales pasos. De acuerdo a su importancia, estos portezuelos y sectores eran sacralizados, situación que se observa claramente en Chada.

Las fuentes documentales europeas estudiadas no aportan evidencia concluyente. Si bien la mención a un puente inca sobre el río Maipo asegura que existió un camino, no hay ninguna referencia respecto de su procedencia. En cuanto a su continuación en dirección sur, hay claridad de que lo hacía hacia el tambo de El Principal y luego a dos portezuelos diferentes. Después de eso, sus respectivas continuaciones entran en un limbo. El mapa de 1617 (fig. 2) muestra un camino de caballos que unió El Principal de Pirque con el sector de Angostura de Paine y Aculeo, utilizando posiblemente uno de estos portezuelos. Se desconoce hacia dónde continuaba el camino viejo por el segundo portezuelo. Odone (1997) supone que iba en dirección al portezuelo de Chada. El mapa en referencia no dibuja ningún camino por dicho portezuelo, lo que indica que, de haber existido, dejó de utilizarse en tiempos hispánicos tempranos.

Tampoco existe claridad respecto de la continuación del camino desde "puente viejo" en el río Maipo hacia el norte. Lo más probable es que hubo una bifurcación, con una ruta que conectó con el centro administrativo inca principal del Mapocho (actual Plaza de Armas de Santiago) y otro con el sector de Apoquindo, en el mismo valle. La distancia en línea recta desde el tambo viejo de Apoquindo hasta el tambo de El Principal (Pirque) es de 22,6 km, y entre el centro administrativo principal y El Principal es de $29 \mathrm{~km}$, distancias posibles de abarcar en un día de marcha. 


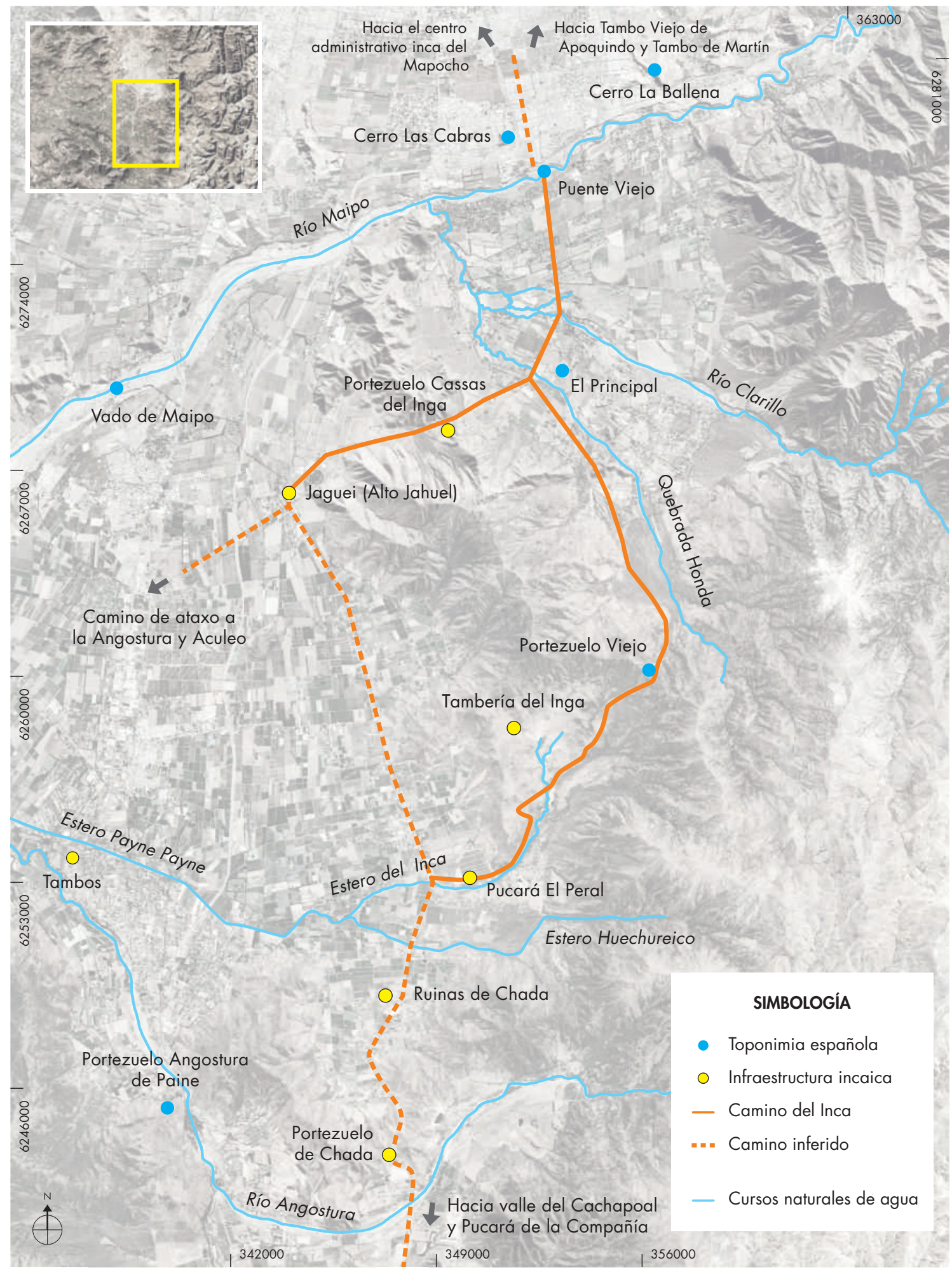

Figura 3. Reconstrucción hipotética de la red vial incaica del curso medio del río Maipo. Figure 3. Hypothetical reconstruction of the Inca road network of the middle course of the Maipo river. 


\section{Camino real a los promaucaes}

Existe información documental de que este camino atravesó La Cañada (actual Alameda del Libertador Bernardo O'Higgins) de la ciudad de Santiago rumbo al sur por la actual avenida Nataniel Cox, siguiendo por Gran Avenida y cruzaba por el pie oriental de los cerros de Tango, actual Chena. En cambio, su continuación hacia el norte nos es desconocida. Un documento de 1547 dice:

Por la presente damos a vos, Marcos Veas, vecino de esta dicha ciudad, de una estancia en tierras de Guachinpilla vuestro cacique, que son en el término y jurisdicción de esta dicha ciudad. La cual dicha estancia y tierra son desde una acequia que se llama Charamábida, yendo por el camino real acial río Maipo, hasta la primera acequia, que es madre que sale del dicho río y llamase el acequia de la Cruz (Actas del Cabildo de Santiago 1861: 126).

En la posesión de las tierras de Tango otorgadas a Gonzalo de Toledo en la década de 1590, se indica que "fuimos a los cerrillos por donde entra el camino real de la ciudad de Santiago, por donde atraviesa una acequia que antiguamente dicen los Ingas sacaban agua" (Actas del Cabildo de Santiago 1861: 316). Al ser mensuradas por Ginés de Lillo "se puso en el camino real que viene de la ciudad de Santiago, que va a los promaucaes, que es en los cerros que llaman de Tango [...] vienen a dar la acequia vieja del Inca, que llaman de Alonso de Córdoba" (Actas del Cabildo de Santiago 1861: 316). Cabe mencionar que la acequia de Alonso de Córdoba era la acequia de Lo Espejo o actual canal Espejino (Hipoteca de Martín Marticorena ante Melchor Román, 1792. ARNAD, NS, tomo 1, f. 432v).

El pucará de Chena, emplazado en el cordón montañoso del mismo nombre a $4 \mathrm{~km}$ al poniente del camino, debió cumplir, entre sus múltiples funciones (Stehberg 1976; La Mura \& Sánchez 2016), una actividad de vigilancia sobre esta importante ruta. El camino continuaba de allí hasta el sector denominado Vado del Maipo, donde cruzaba el río. El 10 de diciembre de 1546, Gerónimo de Alderete recibió del Cabildo de Santiago una merced de tierras que luego compró Gonzalo de Toledo a su viuda Esperanza de Rueda, en 1592. La mensura de estas tierras, efectuada los días 11 y 12 de diciembre de 1546, señaló que ella

[...] començo el primero moxon de los çerrillos (de Tango o Chena) por donde atraviessa una açequia por donde otros tienpos los yngas solian llevar agua a las tierras desta çiudad de santiago y desta manera el primer moxon va por el camino rreal que ba a los promocaes que ba al bado del rrio (RA, vol. 2878, pieza 1, fs. 11 y ss.).

Traspasado el vado, el camino real pasaba un poco al oriente de un cerro muy pequeño llamado Tablongo (hoy denominado Bellavista), como se desprende de una merced del 6 de junio de 1580 por Martín Ruiz de Gamboa a Diego García de Cáceres: "Y junto al río del Maipo pasado el vado del camino real estaba un pedazo de tierras baco [...] pasado el bado del río a la mano derecha del cerro del Tablongo" (RA, vol. 2845, pieza 7, f. 219).

En consecuencia, el camino real del vado o bado pasaba al oriente de los cerros de Tango, Lonquén y Tablongo, por lo cual también fue conocido como camino real de Tango (fig. 1), siguiendo un trayecto bastante similar a la actual carretera Panamericana, con el vado bastante cercano al también actual puente de dicha ruta. El camino siguió rumbo sur, denominándose en este sector camino real de carretas del vado a la Angostura y cruzando el cordón transversal de Angostura de Paine por el paso de La Angostura (fig. 4).

El origen prehispánico de gran parte de esta ruta está fuera de discusión, pero ¿era realmente un camino construido o reconstruido por el Tawantinsuyu? Los caminos del Inca eran instalaciones viales a las cuales se las dotó de una serie de mejoras bastante estandarizadas que facilitaron y agilizaron el desplazamiento de animales de carga y personas. Entre los arreglos más destacados se contaban la mejora de su geometría (linealidad), la preparación del sustrato (despeje de piedras, raspado), la demarcación y protección (línea de piedras a uno o ambos costados, señalización), y el sellado (pavimentos). Además, se los dotaba de instalaciones de descanso y alojamiento (chasquiwasis, tambos), de apoyo (puentes, escaleras) y de vinculación a las deidades tutelares y cosmológicas (saywas, apachetas, plataformas ushnu). Algunos de estos elementos pueden ser identificados actualmente por la arqueología, otros quedaron registrados en la documentación colonial, en la tradición oral y en la toponimia (Hyslop 1984; Berenguer et al. 2005; González 2017).

El camino que hemos designado como Camino del Inca principal o Qhapaq Nan, entre el valle del Maipo y el paso de Chada en el cordón de Angostura, cuenta con evidencias de varios de estos elementos. Por ejemplo, la documentación europea temprana registró 


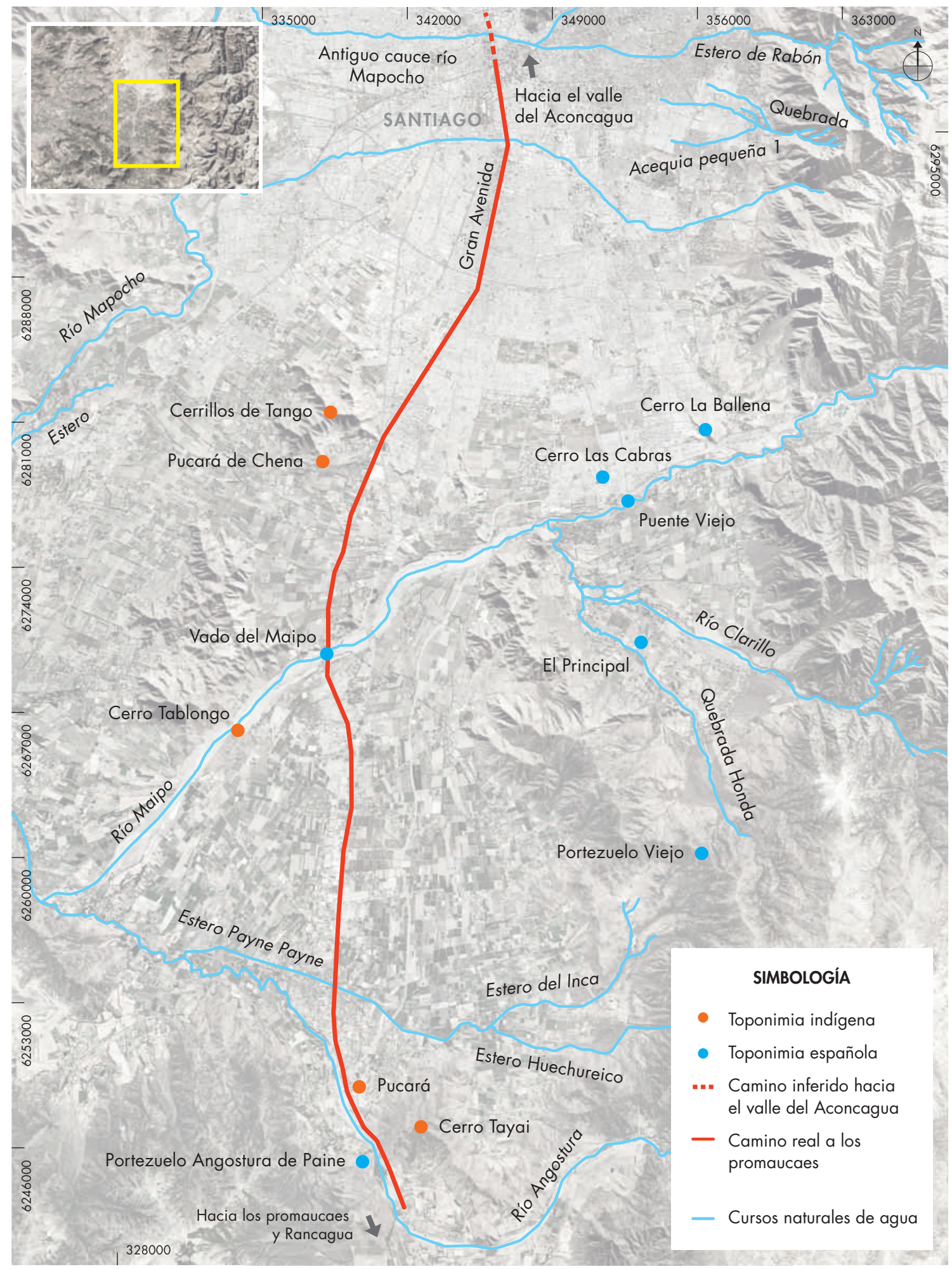

Figura 4. Reconstrucción hipotética del camino real a los promaucaes. Figure 4. Hypothetical reconstruction of the Inca royal road to the promaucaes. 
la existencia de un puente inca o puente viejo sobre el río Maipo, de un tambo en El Principal de Pirque y del portezuelo Casas del Inga, en el camino hacia “jaguei” (actual Alto Jahuel). La toponimia ha conservado el nombre de Estero del Inca; a su vez, la arqueología ha descubierto las ruinas del fortín El Peral en Estero del Inca, las Ruinas de Chada en la rinconada del mismo nombre y la fortaleza de Cerro Grande de La Compañía (Cerro del Inga) en el valle del Cachapoal; todas directamente vinculadas al mencionado camino.

Por el contrario, el camino real a los promaucaes carece de varios de estos elementos. Aparte de cruzar la "acequia vieja del Inga" y pasar junto al "pucara del Inga" en el sector de Hospital, no se registran evidencias arqueológicas y documentales de mejoras viales incaicas. El río Maipo era cruzado por un "vado" y no por un puente colgante, y la toponimia tampoco conservó referencias acerca de la presencia inca, a excepción del cerro Tayai, en el paso La Angostura, que constituyó una guaca principal. Por estos motivos, pensamos que este camino indígena era contemporáneo y posiblemente anterior al Tawantinsuyu, siendo reutilizado durante ese período sin introducir mejoras significativas. Este camino se dirigía hacia terrorios denominados por los incas Purun Auca, "gente rebelde" o, como señaló Vivar, "lobos monteses", aludiendo al carácter indómito y salvaje de sus habitantes. En tiempos hispánicos el nombre derivó a camino real a los promaucaes.

Un detallado croquis de los dos caminos existentes en 1845 entre Santiago y Rancagua (MI, vol. 80) muestra la continuidad en el uso de ambos caminos. A mano izquierda se observa el camino real de La Angostura (de Chada), con "puente de tablas" sobre el Maipo y, a la derecha, el camino real de Tango a los promaucaes, con "puente de cordeles" sobre el mismo río, en el antiguo sector del "vado" (fig. 5).

\section{Distritos poblacionales durante el Período Tawantinsuyu}

A continuación, se analizan los sectores donde hubo concentración de población autóctona y foránea durante el período de influencia incaica. Como se mencionó anteriormente, el término distrito se refiere a la subdivisión de un territorio o población en el contexto de la relación centro-periferia que se estableció al interior de la provincia incaica del Mapocho.

\section{Distrito Pirque (Cochoncachi/Cochoncagi), El Principal (Renguanelén) y Río Claro (Clarillo)}

Una síntesis geográfica, arqueológica, etnohistórica e histórica de este distrito fue realizada por Cabeza y Tudela (1985). Con respecto a ocupaciones prehispánicas informan acerca de los aleros rocosos Caletón de Acosta y Andetelmo, al interior de la cordillera, ambos con restos pertenecientes a la cultura Aconcagua, con presencia de una vasija globular con boca ancha, sin asas ni decoración, en perfecto estado; fragmentos de cerámica anaranjada y restos líticos, entre los que destacan raspadores, cuchillos y perforadores. Como evidencia del Período Incaico reproduce un cántaro zoomorfo con cola, cuerpo ovoidal, boca y asa amplia, decorado con un diseño de origen cuzqueño encontrado en El Principal y que fuera publicado por José Toribio Medina (1882).

A partir de evidencias etnohistóricas, los autores postulan que el río Claro o Clarillo, El Principal y el sector de Pirque estuvieron bajo el dominio inca, destacando como evidencia el tiesto cerámico antes descrito, "la mención manuscrita de un 'tambo' conectado a un camino que, a comienzos de la conquista española, atravesaba las tierras de Pirque y El Principal rumbo a Rancagua" (RA, vol. 2881. Citado en Cabeza \& Tudela 1985: 17), y un puente incaico sobre el río Maipo, cerca de la desembocadura del río Clarillo. Además, la forma de distribución de las tierras y el poder político de los "caciques" de la localidad, refleja un patrón de organización de influencia inca. Evidencia arqueológica de este tambo no se ha encontrado.

$\mathrm{Al}$ inicio de la conquista castellana, los indígenas de río Clarillo y tierras de Pirque fueron entregados en encomienda a los españoles Alonso de Córdoba y Rodrigo de Quiroga. Sumaban aproximadamente 300 individuos y parte de ellos estaban sujetos a los caciques Andetelmo, Gunllanca, Lien Nagual y Nastua Ronco (RA, vol. 2881, f. 111. Citado en Cabeza \& Tudela 1985: 20). Los topónimos originarios fueron Pirqui, Calbue, Quilligue y Cochoncachi. A fines del siglo xvi quedaban tan pocos indígenas que el encomendero Rodrigo de Quiroga decidió reagruparlos y reorganizarlos en otro lugar, como reza la siguiente cita documental:

El cacique Lien Nagual con su hijo Nastua Ronco con más de cien indios subjetos suyos que sembraron y cultivaron dichas tierras de suerte que obedece (habiéndose) ydo muriendo y acabando y quedan tan pocos que los mudó 


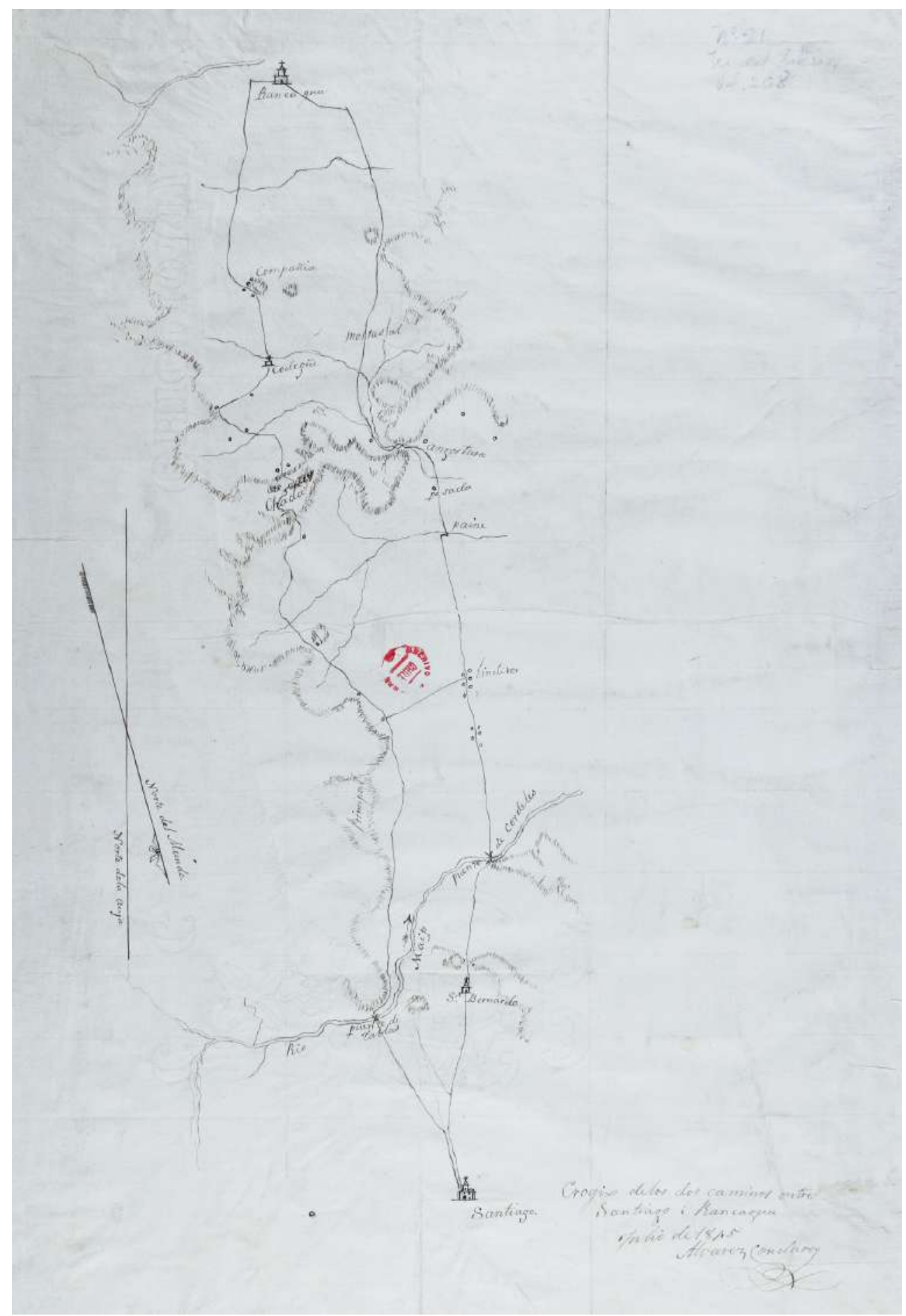

Figura 5. Croquis de los dos caminos entre Santiago y Rancagua, 1845. A la izquierda, el camino real de La Angostura (de Chada), con "puente de tablas" sobre el Maipo y, a la derecha, el camino real de Tango a los promaucaes, con "puente de cordeles", en el sector del "vado". Figure 5. Sketch of the two roads between Santiago and Rancagua, 1845. To the left, the Inca royal road of the Angostura (of Chada), with "plank bridge" over the Maipo and, to the right, the Inca royal road of Tango to the promaucaes, with "rope bridge" by the ford. 
el dicho adelantado al pueblo y tierras de Apoquindo (RA, vol. 2881, f. 111. Citado en Cabeza \& Tudela 1985: 21).

Las primeras mercedes de tierra fueron entregadas a Alonso de Córdoba el Mozo, encomendero de El Principal, a Pedro Tobar, a Francisco Muñoz y a Pedro Miranda (Cabeza \& Tudela 1985: 22). En 1603, Juan Fernández de Córdoba, hijo de Alonso de Córdoba el Mozo compró al cacique Sebastián Licapillán las tierras de río Clarillo "en la cantidad de 200 ovejas, 50 cabras, algo de ropa, una yunta de bueyes, un sobrero y otros enseres" (RA, vol. 214. Citado en Cabeza \& Tudela 1985: 22). Posteriormente, en 1618, el mismo Juan Fernández de Córdoba compró a su vecino Juan Álvarez de Tobar la estancia de Pirque que comprendía unas 500 cuadras de tierras de la otra banda del río Maipo, entre el dicho río y el río Claro de El Principal, formando una de las más importantes estancias de la región de Santiago (RA, vol. 214, f. 316. Citado en Cabeza \& Tudela 1985: 22). Finalmente, el 13 de septiembre de 1580, en la posesión de las tierras otorgadas a Alonso de Córdoba el Mozo, se señala que,

[...] estando en el tambo del dicho principal de maipo y corral de yeguas $[\ldots]$ ciento y cincuenta cuadras desde el tambo y corral de yeguas de cabezada y por moxon la cuesta del camino real que ba a hospital desta ciudad de Santiago (RA, vol. 214, fs. 122 y 122v).

Una profundización de este estudio fue realizada por el equipo de Ángel Cabeza por medio del proyecto FONDECYT n. ${ }^{\circ}$ 91-1021. Dicho estudio dio origen a un artículo del cual se extrae la información que sigue (Gómez et al. 2014).

Una prospección arqueológica realizada en el sector Divisadero del río Clarillo permitió identificar restos de bases o improntas de viviendas, instrumentos de molienda, fragmentos de cerámica y una posible acequia de un metro de ancho con orientación $\mathrm{O}$ a E, atribuibles a la cultura Aconcagua.

La información documental temprana se refiere a la presencia de sistemas de irrigación prehispánicos: “[...] toda es tierra llana y rrasa y esta azequiada y surcada de los antiguos y es la parte más fértil de lo que fue el dicho Juan de Córdoba" (RA, vol. 214, f. 216v. Citado en Gómez et al. 2014: 71). El resto del valle estaba ocupado de manera similar: "[...] todo un valle con el de pirqui y guilligui [...] lo ocuparon y cultivaron todo como se manifiesta oy dia por las azequias antiguas conque regaban dicho valle y llanada y con esta consideración se hizo la merced por el dicho nombre de cochoncachi" (RA, vol. 214, f. 66v. Citado en Gómez et al. 2014: 71). Para el Principal de Pirque se especifica que "las azequias de los indios y sus tomas (estaban) en la misma voca del potrero de la madera y cerro Quillin" (RA, vol. 214, f. 142v. Citado en Gómez et al. 2014: 71).

Con respecto a las encomiendas, se señala que los indígenas del pie de montaña fueron encomendados a Alonso de Córdoba el Viejo, en tanto que otras parcialidades de

[...] más de ciento cincuenta indios [fueron puestos] en el adelantado don Rodrigo de Quiroga, el cual por amistad y correspondencia voluntaria dio al cap. Juan de Queba el cacique Andetelmo y a su hijo Gunllanca con los indios [...] y los llevó al valle y tierras de Niltunque [...] y solo quedó en las dichas tierras el cacique Lien Nagual con su hijo Nastuarongo con más de cien indios subjetos suyos que sembraron y cultivaron las dichas tierras de suerte que por aberse ido muriendo y acabando y quedan tan pocos mudó el dicho adelantado al pueblo y tierras de Apoquindo [...] y la división que hay es la del rio Claro que divide las tierras de los indios del cap. Alonso de Córdoba (RA, vol. 2881. Citado en Gómez et al. 2014: 71).

Aparentemente, al igual como lo fue el estero de Rabón en el valle del Mapocho, el río Claro fue una división étnica entre parcialidades indígenas del Maipo.

En febrero de 1603, un esclavo negro llamado Valentín mencionó en un proceso de sucesión y ventas que fue a poblar la estancia del Principal de Córdoba junto a su amo, el licenciado Juan de Morales, y otros esclavos que compró al capitán Alonso de Córdoba:

[...] y la poblaron en el mismo tambo y pueblo de los indios donde era la iglesia $[\ldots]$ y en esta ocasión rretiro los indios que estaban en el dicho tambo el dicho Alonso de cordoba al sitio de los baños rrio arriba donde estaba el casique Sebastián Licapillan y otros muchos indios [...] y que de la banda del rrio Claro entre él y el dicho tambo estaba otra parcialidad de indios con el casique don Pedro millanguire (RA, vol. 214, f. 27v. Citado en Gómez et al. 2014: 72).

Otro documento fechado el 13 de febrero de 1603 especifica que el Principal del Maipo se llamaba originalmente Renguanelén y que, a la sazón, el cacique era Sebastián Licanpillán, de la encomienda de Alonso de Córdoba, propietario de las tierras de Calebue y Pirque, entre el río Claro y la cordillera hasta el cerro alto de Quellín: "[...] y comienza desde el camino que ba de el puente al dicho principal de Renguanelén, donde antiguamente 


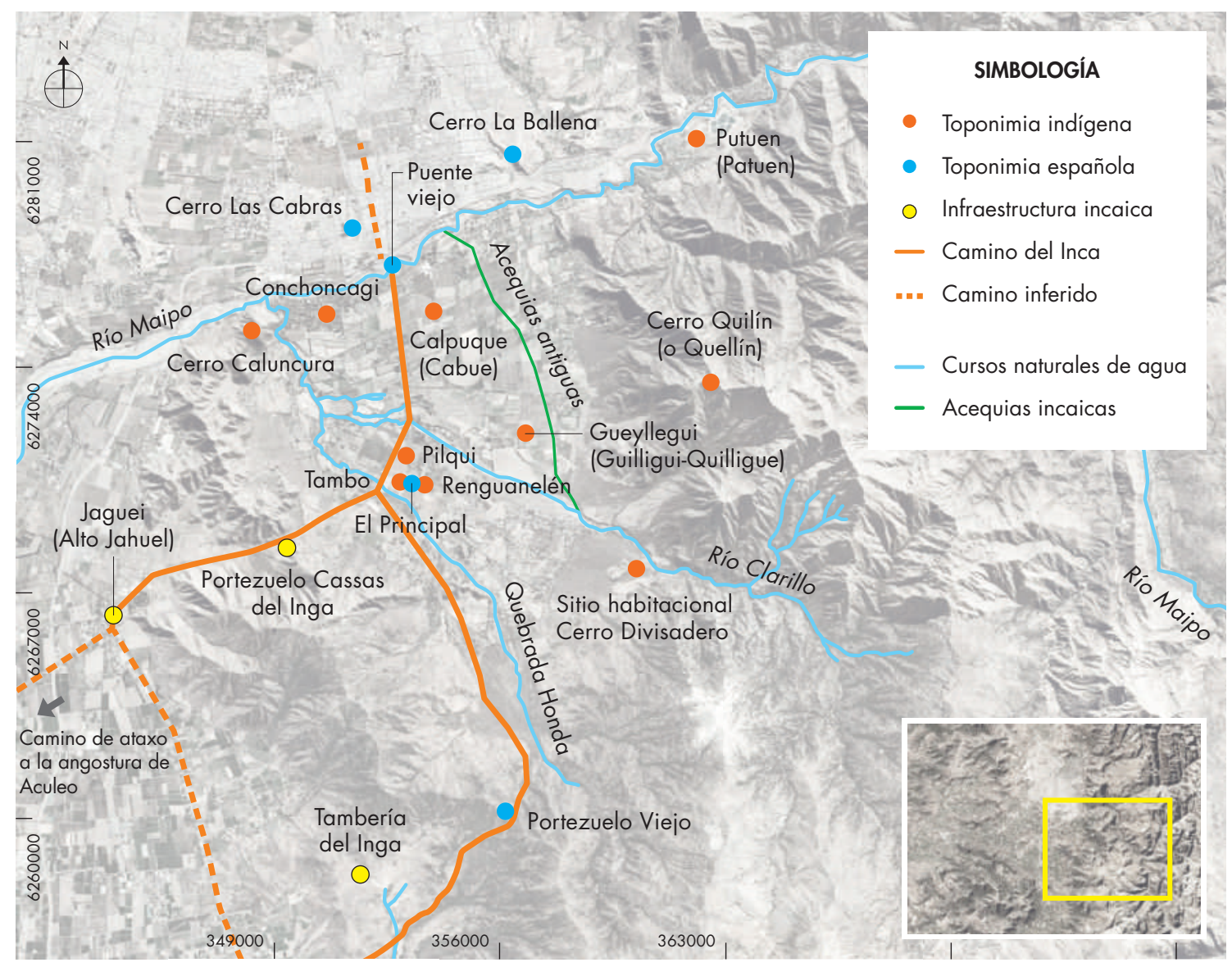

Figura 6. Reconstrucción hipotética del Camino del Inca y principales topónimos del distrito Pirque-El Principal y Río Claro. Figure 6. Hypothetical reconstruction of the Inca Trail and main place names of the Pirque-El Principal and Rio Claro district.

solía estar el tambo y iglesia" (Fv, vol. 270. Citado en Gómez et al. 2014: 73). Una reconstrucción del distrito puede verse en la figura 6 .

No quedan dudas respecto de la ocupación incaica de Pirque, El Principal y el curso inferior del río Claro, con presencia de un canal principal y acequias secundarias que regaban el valle y un extenso llano, el asiento del cacique principal del Maipo, Renguanelén -denominado por los españoles como Principal de Pirque y Principal de Córdoba-, un tambo y un tramo del Camino del Inca que conectaba el valle del Mapocho con el cordón de Angostura, atravesando el mencionado "puente viejo" sobre el río Maipo.

La revisión de documentación histórica temprana entregó otros topónimos del área. El 28 de marzo de 1590, el gobernador Alonso de Sotomayor cedió a Cristóbal Álvarez Tobar 200 cuadras de tierras en
Cochonchachi, las que dieron origen a la estancia Santa Rita de Pirque. Cochonchachi o Cochoncagi correspondió a una rinconada hacia la cordillera, localizada a mano izquierda del camino que venía de Santiago y que, tras pasar el puente del Maipo, cruzaba el cordón de cerros Los Ratones en dirección a la Angostura (RA, vol. 2881, pieza 1, f. 198). Cabe mencionar que Cochoncagi podría provenir de las palabras en mapuzungun $\mathrm{Co}$, chon y cavi: la primera es agua, la segunda es un ave mitológica, y la última denomina a una agrupación de alrededor de 300 familias. Si se recuerda que 150 indígenas fueron encomendados a Rodrigo de Quiroga, otros a Alonso de Córdoba el Viejo, quedando en las tierras el cacique Lien Nagual con más de 100 indios, estamos aproximadamente en el número de familias que componían un cabi o cavi (Stehberg \& Sotomayor 1999). 
El 4 de enero de 1578, el gobernador Rodrigo de Quiroga otorgó una merced de tierra a Alonso de Córdoba el Mozo, en tierras del cacique Principal de Córdoba (RA, vol. 214, f. 119). El 9 de octubre de 1608, el gobernador Alonso García de Ramón concedió a Salvador Careaga Ortega el valle de Putuen o Patuen, en Pirque Alto, conformando la estancia conocida posteriormente como San Juan de la Sierra (ES, vol. 258, f. 224, 1663. Valle de Putuen o Patuen) y, a principios de siglo XVII, el gobernador Alonso de Ribera otorgó una merced de 200 cuadras a Cristóbal Álvarez Tobar y una de 300 cuadras de tierra a Juan Álvarez Tobar, en tierras de Santa Rita de Pirque (Izquierdo 1982).

\section{Distrito Estero del Inga y Chada}

Existe abundante información arqueológica y etnohistórica relativa a la presencia preincaica e incaica en la rinconada de Chada. Con respecto a la cultura Aconcagua que ocupaba el área antes de la expansión Tawantinsuyu, se han efectuado estudios en los sitios Turbinas 1 y Turbinas 2 (Stehberg et al. 1996; Planella \& Stehberg 1997; Pavlovic et al. 2019). El primero se localiza al pie NO de la cerrillada Ruinas de Chada, el segundo se ubica a 1 $\mathrm{km}$ al SE del primero. Ambos correspondieron a sitios residenciales con evidencias de estructuras habitacionales y restos de molienda y material cerámico. Las ocupaciones se iniciaron a principios del siglo $\mathrm{x}$ (fechado $\mathrm{TL}$ de $910 \pm 95$ AP o 1085 DC) y se extendieron hasta el período de contacto incaico. Ambos sitios ocuparon una superficie de casi 10 hectáreas. Si a ello agregamos que casi toda la superficie de la rinconada presenta restos arqueológicos de distintos períodos, se concluye que Chada fue densamente poblada en el período prehispánico.

En el valle del Maipo en general y, específicamente, en los sitios Turbinas 1 y Turbinas 2, en Collipeumo (sitio vp8) y en San Agustín 3 y San Agustín 4 de Calera de Tango,

[...] el material de estilo Inka en sitios domésticos es prácticamente inexistente, siendo los materiales que denotan ocupaciones del Período Tardío casi en su totalidad escasos fragmentos pertenecientes a piezas locales de fase Inka o cerámica local con decoraciones que denotan su pertenencia a este período (Pavlovic et al. 2019: 55).

Sus dataciones, en tanto, confirman su contemporaneidad con las ocupaciones detectadas en los complejos arquitectónicos asociados.
Sobre una de las dos cumbres gemelas de una pequeña cerrillada, con amplio dominio de la rinconada y del camino incaico, el Tawantinsuyu emplazó un sitio de arquitectura compleja, caracterizada por dos cimientos perimetrales de piedra y una serie de recintos y almenas de muros bajos dispuestas simétricamente siguiendo el principio de dualidad, tripartición y cuatripartición. La presencia de doble muro de $80 \mathrm{~cm}$ de ancho, fragmentos cerámicos con decoración cuzqueña y los fechados TL de $510 \pm 60$ AP ( 1475 DC) y $500 \pm 55$ AP (1490 DC), lo asignaron al Período Tawantinsuyu (Stehberg et al. 1997). Un agujero central, interpretado como ushnu, le asignó al sitio una función ceremonial. Se trataría de una instalación importante, seguramente de rango estatal, la cual fue denominada por los arqueólogos "Ruinas de Chada".

Luego de su descubrimiento y de los primeros estudios, este sitio ha sido objeto de varias investigaciones arqueológicas, arqueoastronómicas y patrimoniales que han incrementado su conocimiento e importancia. El equipo liderado por Daniel Pavlovic concluyó que todo el conjunto se planificó desde un lugar ubicado en el punto central y más alto del sitio, utilizando

[...] principios como la reflexión desplazada y la reflexión tipo espejo, a través de la línea eje y la traslación, y produce una figura que recuerda los movimientos alternados, derechaizquierda; reconocidos en los patrones propuestos, puestos en otras materialidades, como es el caso de los diseños de las vasijas de estilo o influencia inca, tanto en la zona [...] como en áreas aledañas (Pavlovic et al. 2019: 64).

Se plantea un acceso normado y restringido a pequeños grupos que desarrollaron actividades relacionadas con la ritualidad incaica y la observación astronómica ligada al calendario agrícola, tal como lo señalaron Ruano (2012) y La Mura y Sánchez (2016). La interacción entre arqueología, patrimonio y comunidad local fue abordada por Silva y colaboradores (2017).

Un pequeño reducto fortificado de cumbre fue hallado en cerro El Peral, a 720 msnm, al interior del fundo El Peumo de propiedad de Andrés Pérez Cruz, en el sector de Huelquén, comuna de Paine, a unos 5 $\mathrm{km}$ al NNE de las Ruinas de Chada. El "sendero antiguo del Principal de Córdoba a Chada por Quebrada del Inca" pasaba a sus pies, reforzando la hipótesis de que la función del sitio El Peral fue para su control y protección (Stehberg 2013: 143-144). El patrón arquitectónico de doble muro de piedra canteada, la cerámica y un fecha- 
do por termoluminiscencia de 580+55 AP (1475 DC) confirmaron la adscripción del sitio al Tawantinsuyu.

Gerónimo de Vivar, el primer cronista de Chile, enterado de la importancia que le asignaban los indígenas al cordón de Angostura, efectuó una visita especial al sector señalando:

Esta provincia de los pomocaes que comienza de siete leguas de la ciudad de Santiago, que es un angostura y ansi le llaman los españoles estos cerro que hacen una angustura. Y aquí llegaron los yngas cuando vinieron a conquistar esta tierra. y de aquí adelante no pasaron. Y en una syerra de una parte de angustura hazia la cordillera toparon una boca y cueva, la qual está hoy en día y estara. Y de ella sale viento y aún bien rrezio. Y como los yngas lo vieron fueron muy contentos, porque dezían que habían hallado ' guayra vaci', que es tanto como sy dixese 'la casa del viento'. Y allí poblaron un pueblo, los cuales symientos están oy en dia, y no digo de ellos por estar tan arruinados (Vivar 1979 [1558]: 164).

La descripción del cronista parece coincidir con la ubicación de las "Ruinas de Chada" y con una caverna, como se verá a continuación.

Respecto a guayra vaci, un importante cronista del Perú fue informado que

[...] había en este tercero camino [el del Collasuyu] nueve ceques y en ellas ochenta y cinco adoratorios o guacas [...] La octava, Guayra, es una quebrada de la Angostura a donde contaban que se metía el viento. Hacíanle sacrificio cuando soplaban recios vientos (Cobo 1890-1893 [1653], vol. 4. Citado en Odone 1997: 191).

Se desconoce si esta cita se refiere al sector de Chada o describe otra cueva similar en otro lugar del Collasuyu.

Cabe mencionar que en Culitrín, $2 \mathrm{~km}$ al poniente de las Ruinas de Chada, existió una caverna profunda conocida como Cueva del Cura y cuya boca fue dinamitada por los lugareños por considerar que estaba embrujada. Es posible que formara parte de un antiguo curso de agua subterráneo y se conectara con la Cueva de la Vieja, en el lado opuesto del cerro, situación que permitiría el paso de aire y, de allí, la denominación de "guayra vasi o casa del viento".

Odone (1997) proporciona una interesante cita obtenida de la mensura del "pueblo de indios de Chada”, en 1675:

[...] les dio dose quadras y dos de ancho y otras tantas en largo que hisieron ciento y sinquenta quadras y en ellas quedo incluso el pueblo antiguo ranchos y arboledas de los dichos indios y el paraje del Tambo de dichos indios (RA, vol. 857, pieza 1, 1689, f. 58v. Citado en Odone 1997: 203).
La referencia a pueblo antiguo recuerda la cita del cronista Vivar cuando mencionó “allí poblaron un pueblo”. El adjetivo antiguo era la manera como los españoles se referían a prehispánico. La mensura señala expresamente que el tambo estaba en un paraje distinto al pueblo, el cual, por lo demás, constaba de "ranchos", es decir, la casa de quincha y paja tradicional de los indígenas locales, lo que remite a funcionalidades distintas, pero ocupadas por el mismo grupo humano.

Llama la atención la ausencia de toda mención al uso de acequias durante el siglo xvi. Las pocas referencias que se han encontrado de ellas corresponden a la segunda mitad del siglo xvir, formando parte del pueblo de indios de Chada: "[...] que los dichos indios no tienen sembradas sus chacras, por la poco agua que uiene por su asequia y ase mesmo de la que lleua la que tiene sacada el sargento mayor don Juan Gallardo..." (RA, vol. 857, pieza 1, 1689, f. 50v. Citado en Odone 1997: 199). Destaca la referencia a la "arboleda" para el pueblo antiguo, lo que sugiere la importancia de contar con estos recursos vegetales (leña, alimentos, material de construcción). Para otros detalles de este pueblo y la disminución de sus habitantes, remitimos a Odone (1997).

"Los cerros Batumichi (Batunachi, Batunichi), Turun y Tayay, el estero Guegueyco (Huechureico) y del Inca, los Potreros, Pillan y Colicom (Colicolem) son parte de la cartografía indígena del valle de Chada" (Odone 1997: 206), lo que significa que, en ese entonces, existía la noción del espacio andino por parte de los españoles. Era creíble, entonces, todo lo que contaban los indígenas, pues de no ser así no sabrían los linderos de sus cuadras de tierra.

El agrimensor "queriendo continuar la dicha mensura para el estero del Inca lo contradijeron los indios del pueblo de Chada disiendo no aver sido las dichas tierras pertenecientes al dicho pueblo" (RA, vol. 857, pieza 1, 1689, f. 57r. Citado en Odone 1997: 205). Esta cita es interesante porque muestra que los habitantes del pueblo de Chada recordaban y respetaban que las tierras del Estero del Inca no les correspondían ya que, como su nombre lo indica, pertenecieron a la autoridad Tawantinsuyu. Esto lleva a postular (fig. 7) una incipiente división de la tierra para este distrito, con una parte dedicada a satisfacer las necesidades del Estado incaico (Estero del Inga) y la otra a la comunidad local (Chada).

Las tierras de Pachacayca en Chada son mencionadas en la entrega de tres mercedes (dos sin fecha y 


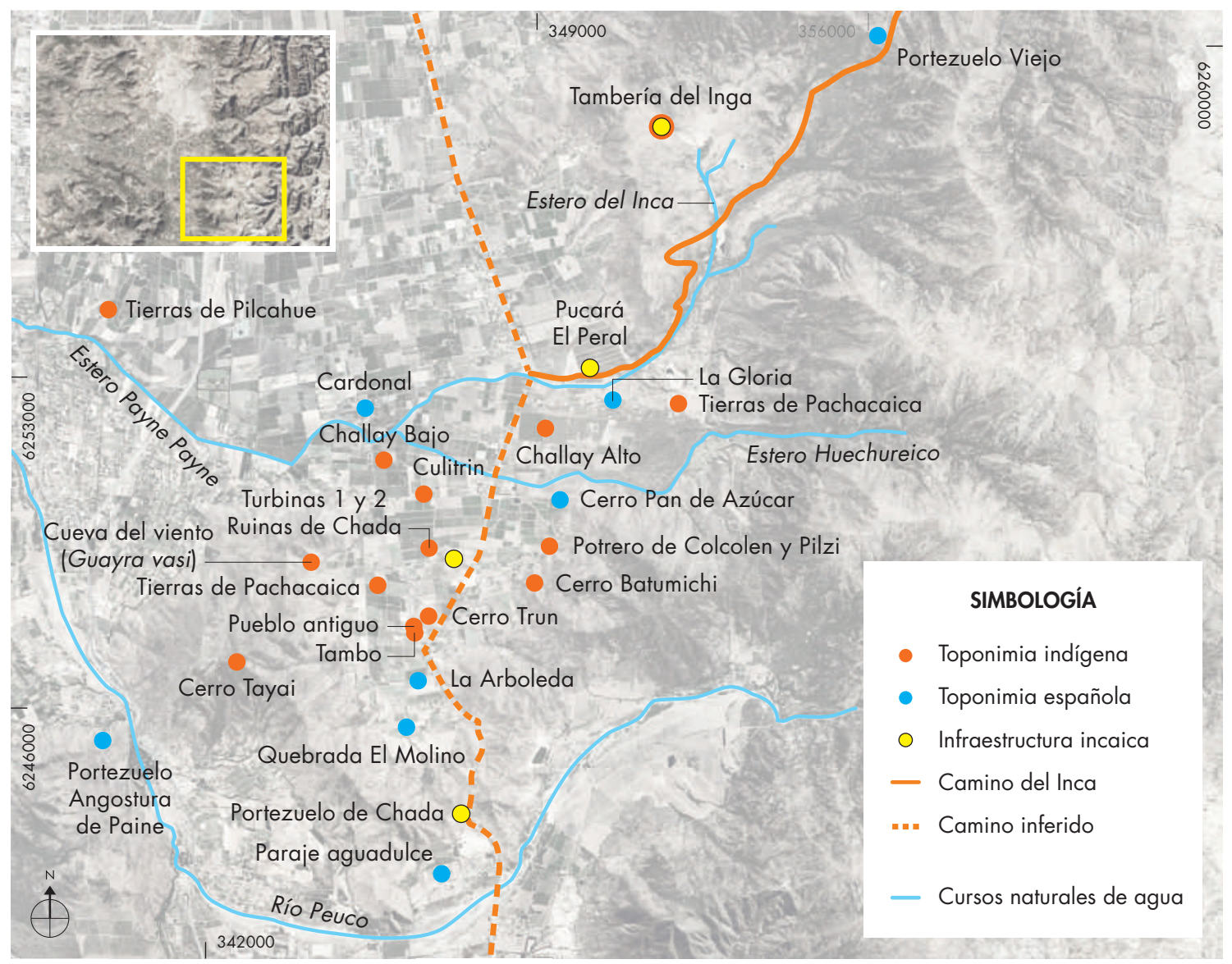

Figura 7. Reconstrucción hipotética del Camino del Inca y principales topónimos del distrito Estero del Inga y Chada. Figure 7. Hypothetical reconstruction of the Inca Trail and main place names of the Estero del Inga and Chada district.

la última de 1605) de 1500 cuadras por parte de los gobernadores Alonso Sotomayor y García Ramón a Francisco Villagra, conformando la estancia de la Gloria (Es, vol. 144, f. 94, 1648). Pachacayca es voz quechua, en la que pacha designa la tierra. Por su parte, las tierras de Pilcahue en Paine (estancia de los Jaraquemada) constituyeron el linde norte de la estancia de Juan Álvarez Berrío en Chada.

\section{Distrito Paine}

La estancia denominada de Paine estuvo en poder de la familia Jaraquemada desde inicios del siglo xvir hasta el siglo XIx. Esta estancia se encontraba inmediatamente al norte de las estancias de Chada y del Hospital, separada de ellas por el estero de Paine Paine. Es probable que esta estancia haya sido la primera que poseyó el Hospital
San Juan de Dios en el sector de Angostura, pues ya en la merced de tierras de Tablongo de Diego de Cifontes de Medina de 1580 se la cita como lindero sur. Apoya esta idea la mención del padre Miguel de Olivares en su Historia de Chile, donde afirma que don Pedro de Valdivia dotó al Hospital con una estancia de tierras en Chada (Olivares 1864). Posteriormente, el Hospital San Juan de Dios trocó estas tierras por una estancia que Juan Muñoz y Beatriz de Bobadilla poseían al poniente de estas tierras. En la escritura de transacción de 1602 entre los herederos de Juan Muñoz y el Hospital, se describen los linderos de esta estancia de Paine:

Las cuales lindan por una parte con el camino real que comienza de esta parte del estero llamado Payne Payne, discurriendo por el mismo camino real que viene de la otra ciudad, que en medio o casi estan ciertos arboles de duraznos donde antiguamente tuvo Diego de Cifontes 
ganados y corrales como mayordomo que era del Hospital y discurriendo adelante hasta llegar con tierras que tiene Cristobal Muñoz, y de alli atravieza hasta la cordillera nevada y discurriendo llegan a un estero cuio nacimiento sale de la otra cordillera llamado en lengua de indios Linca que llega hasta el otro Paine Paine y camino real; y el otro estero llamado Linca alinda con estancia y tierras de Francisco Gomez de las Montañas [estancia en Chada] (FHnss, AD0005. El texto entre corchetes es nuestro).

Esta estancia pasó a manos de Gabriel Muñoz, con el nombre de Paine Paine, de Gabriel Muñoz de Bobadilla (hijo de Juan Muñoz) y luego, en una fecha cercana a 1630, la adquirió Diego de Jaraquemada Solorzano, en cuya familia permanecería hasta mediados del siglo XIX (ES, vol. 56, f. 448 y ES, vol. 73, f. 60).

\section{Distrito Hospital o Belauquén}

La merced de 300 cuadras de tierras en Belauquén otorgada por el gobernador Martín Ruiz de Gamboa a Alonso de Miranda en 1583 señala:

\footnotetext{
Desde el serrillo de los pucaranes del inga hasta el rio de la Angostura y desde la sierra de los indios de Diego García y de la otra parte del cerro de la Guaca (del agua) delinga. Las cuales dichas tierras antiguamente llamaban Belauquén eran de los ingas y en ellas habian tenido sus tambos. Estando en las tierras de Angostura [...] cerca del serrillo donde los ingas tuvieron un fuerte y junto donde los ingas en lo más llano tuvieron edificios de piedras [...] van corriendo [...] teniendo por linderos el cerro que llaman de la guaca delinga (FHNSS, AD0001).
}

Esta cita documental inédita, de la segunda mitad del siglo XVI, es la más completa que hemos encontrado acerca de la presencia incaica en un lugar concreto de la provincia incaica del Mapocho (fig. 8). Describe un paisaje fuertemente incaizado, donde el español utiliza instalaciones, lugares sagrados y topónimos incaicos llenos de significado, para delimitar la merced otorgada: Belauquén, pucaranes del inga, tambos, guaca del inga, edificios de piedras, etc., y la ausencia de toda referencia a acequias y agricultura.

En una merced de 150 cuadras otorgada por Alonso de Sotomayor a Francisco de Toledo en 1584 denominada estancia de Tayai, se mencionan como lindes el cerro de Tayai, el camino real de carretas y un cerrillo llamado el pucará. Además, se menciona explícitamente: "que entran en ellas un serrito que llaman el Pucara" (FHNSs, AD0001, f. 6). El juez de tierras Juan Ortiz de Cárdenas mensuró estas tierras en 1607:

\begin{abstract}
Se puso en una punta del otro cerro que es la mas conjunta y primera en vista al cerrillo de la Guaca que llaman del pucara donde con un cordel de una cuadra de las de la ciudad midió siete cuadras que hicieron fin en un malar grande de madera de palos por del otro Hospital y se puso mojon (FHNSS, AD0005).
\end{abstract}

En una mensura posterior, efectuada el 3 de enero de 1618 por el capitán Liñán de Vera a las tierras ahora de Hernando Álvarez de Toledo, hijo de Francisco, se dice lo siguiente:

Tomo la derecera de la punta del cerro Tayay al pie de el desde donde mando echar la cuerda y hacer un mojon y habiendolo hecho comenzaron a medir sesgando para el cerro que llaman el Pucara del Inga hasta el pie de el por la banda de la Angostura [...] y arrimado al dicho cerro se fueron midiendo 12 cuadras y media [...] y hicieron fin y remate media cuadra delante de el dicho cerro hacia la ciudad de Santiago (FHNSS, AD0001).

También se menciona que hacia el norte de dichas tierras "atravieza los corrales de dicho hospital quedando las casas de la dicha estancia del hospital en tierras que se midieron por el dicho Hernando Álvarez de Toledo y quedaron medidas debajo de los dichos linderos" (FHNSs, AD0001, fs. 198 y 198v).

Este documento sugiere fuertemente tres hechos importantes. Primero, la existencia de un cerrito denominado Pucará del Inga, 12 cuadras al norte del cerro Tayay (lugar donde existe hoy un cerrito isla denominado Algarrobo). Segundo, la presencia de un malar (malal: corral en mapuzungun) de madera, o fortaleza indígena, emplazado cerca del pucará. Y, tercero, la indicación de que las estancias de los Toledo y el Hospital estaban adyacentes una de la otra (veremos la importancia de este punto más adelante). No disponemos del significado en quechua o mapuzungun del topónimo "Tayay”, aunque podría derivar de tatay (padre) del primer idioma. El cerro se conoce actualmente como Challay, y challa significa olla en mapuzungun.

En una venta de tierras de Hernando, cacique de Aculeo, a Juan Muñoz y Beatriz de Bobadilla en 1589, el cacique dijo que "recibió las tierras de su padre y a este se las dio el inga”. Esta propiedad lindaba con tierras del Hospital (San Juan de Dios), propiedad de Domingo de Erazo y de Francisco Gómez de las Montañas y "corren desde los cerrillos del inga por el camino real hasta el rio Paine Paine" (FHNSs, AD0005). Esta notable cita confirma que el representante del Inca repartió tierras en Aculeo y que esta división territorial fue aceptada y validada 


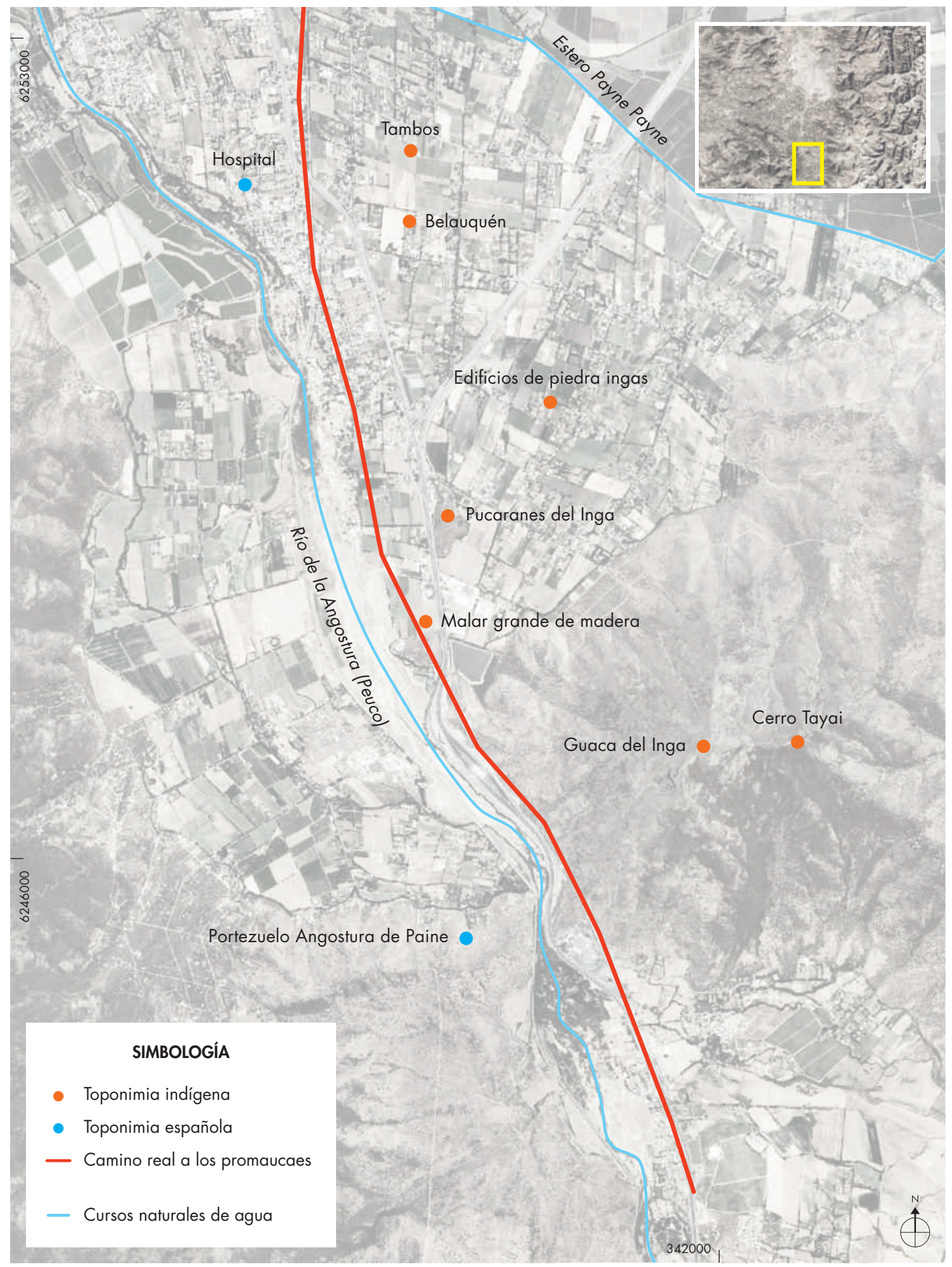

Figura 8. Reconstrucción hipotética del camino real a los promaucaes y principales topónimos del distrito Hospital o Belauquén. Figure 8. Hypothetical reconstruction of the Inca royal road to the promaucaes and main place names of the Belauquén, or Hospital district. 
por la población local. El cacique Hernando justificó ante el español la posesión sobre su propiedad en un acto de entrega realizado por el Inca. En su frase final, la referencia relaciona los cerrillos del inga con el camino real que, como se verá a continuación, iba a Rancagua.

La merced a Domingo de Erazo, en 1594, de tierras que se denominan Catalguano y Copequé, se extendió desde los cerrillos del pucara del inga hasta el estero de Paine Paine y por un lado el camino real del pueblo de Rancagua (FHNss, AD0005). En la merced de 200 cuadras otorgada por Alonso García Ramón a Miguel Gerónimo Venegas el 15 de octubre de 1600 se describe esta ruta como "camino real de carretas" (FHNSS, AD0005).

Todas las estancias mencionadas anteriormente, excepto la de Miguel Gerónimo Venegas, se localizaban en el mismo sector. Esto se puede evidenciar por otra escritura que dice que las estancias de Gabriel Muñoz de Bobadilla (hijo de Juan Muñoz), la de Alonso de Miranda y la de Domingo de Erazo conformaban "un solo cuerpo" (FHNss, AD0001). Además, sabemos que la estancia de Tayay de propiedad de Francisco de Toledo colindaba también con la estancia del Hospital. Esto indica que los pucaranes del inga mencionados en la merced de Alonso de Miranda, el cerrillo del Pucará señalado en la estancia de Francisco de Toledo, los cerrillos del Inga por el camino real que aparecen en las tierras de Juan Muñoz y los cerrillos del Pucará del Inga referidos en la estancia de Domingo de Erazo indican un mismo pucará de origen incaico localizado probablemente en el cerro denominado actualmente Algarrobo, junto a la actual carretera Panamericana. No debe confundirse, por tanto, con el pucará incaico de Collipeumo, en Aculeo.

\section{Distrito Aculeo}

Respecto del pueblo de indios de Aculeo, valgan las citas siguientes. El 26 de abril de 1599, los indios de Aculeo vendieron a Gaspar Hernández de la Serna un pedazo de tierra junto al río Angostura, que en nombre indígena

[...] se llaman Chacome [...] y discurren corriendo por cabezada desde la punta del cerrillo que llaman Collupilegmu [Collipeumo] que está junto al rio de la Angostura hasta dar con una punta de otro cerro BodBod y por otro nombre LLome que está junto con el desaguadero de la laguna y tiene por linderos por los lados del cerro de la otra laguna y mojones de la tierra de Bartolomé del Arco y con tierras que se llaman Chacome y con la puente y cardones que se llama Colue y discurren las otras tierras hasta el rio Maipo (RA, vol. 2845, pieza 7. El texto entre corchetes es nuestro).
Nótese la corrupción gramatical de algunos topónimos indígenas y la interesante referencia a la existencia de dos lagunas.

Acerca del nombre original de la laguna pequeña se sabe que, en 1595, Tomás de Olavarría vendió a Gabriel de Cifontes y Juan Navarro las tierras de Pichicauquén llamadas también Batuco, junto a la laguna de Aculeo, que corrían desde la punta de un cerrillo hasta la lagunilla llamada Pichicauquen (Es, vol. 9, f. 270) (pichi: chico, cauquen: avutarda, ave), reservando a los indios dos cuadras de tierra en redondo de la Laguna Grande.

En fecha no precisada, Melchor Jufré de Águila recibió una merced de 400 cuadras de tierra en Aculeo, siendo confirmadas por el gobernador Alonso de Ribera en 1605 (FHNss, AD005). Estaban en los linderos de la laguna de Aculeo y confines de las tierras de Gabriel de Cifontes y Gaspar Hernández. Posteriormente, fueron vendidas por Melchor Jufré al ya mencionado Gabriel de Cifontes (RA, vol. 2845, pieza 7, f. 158).

El 12 de julio de 1605, el gobernador Alonso García de Ramón otorgó a Simón Díaz Hidalgo dos pedazos de tierra de "500 cuadras en Aculeo, lindando con cerro grande, tambo de Aculeo y con Lolemo media legua río abajo del tambo de Aculeo junto a la boca del desaguadero de la laguna" (RA, vol. 2845, pieza 7). De acuerdo con esta información, el tambo de Aculeo estuvo a $2400 \mathrm{~m}$ río arriba de la boca del desaguadero de la laguna principal llamado Lolemo (fig. 9). No se ha encontrado evidencia arqueológica de este tambo.

En 1606, Alonso Nelquelgueno, hijo del cacique Martín de Aculeo, vendió a Gabriel Cifontes las tierras de Chedqued, Cubulgue y Challacura (RA, vol. 2845, pieza 7). En 1611, los indios de Aculeo vendieron a Gabriel de Cifontes y Francisco Sánchez Navarro, otro pedazo de tierra cerca de Aculeo (ES, vol. 47, f. 48). Sorprendentemente, las fuentes analizadas no se refieren a la existencia de un pucará en el sector, pese a que la arqueología ha confirmado la existencia del pucará de Collipeumo. En cambio, los documentos mencionan la existencia del tambo de Aculeo, el cual no ha sido identificado por la arqueología.

La arqueología ha registrado la presencia de asentamientos domésticos locales en las tierras bajas y llanas, contemporáneos a las construcciones arquitectónicas existentes en algunos cerros como Collipeumo, "generándose un dominio visual y una situación de preeminencia física de toda la sección sur de la cuenca, amparada y reforzada por su conexión visual directa 


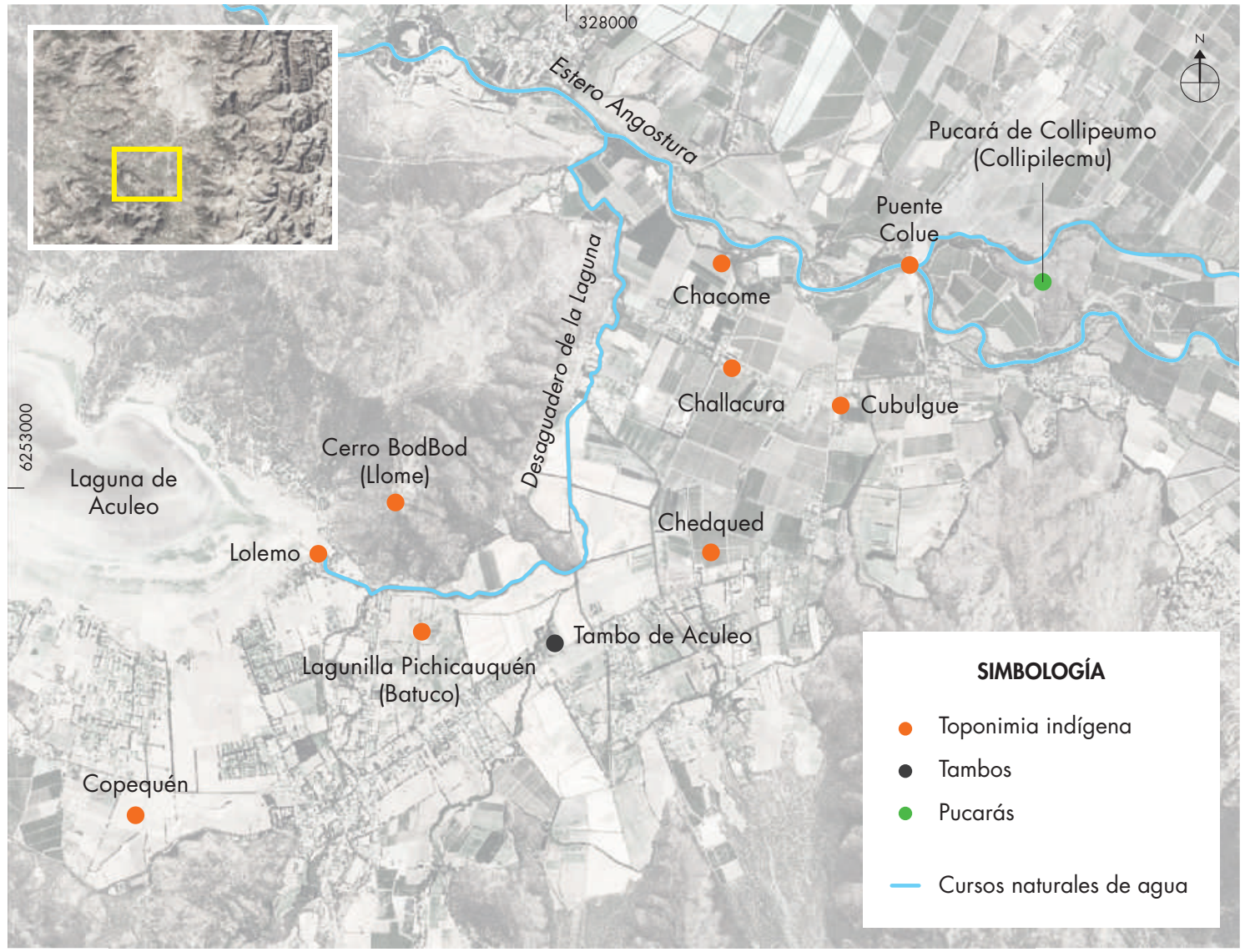

Figura 9. Localización aproximada de los topónimos citados en el texto del distrito Aculeo. Figure 9. Approximate location of the place names of the Aculeo district mentioned in the text.

con las wakas" (Pavlovic et al. 2019: 64). La excavación del sitio VP8 proporcionó un contexto similar a los sitios habitacionales aledaños al pucará de Chena y Ruinas de Chada, con predominio de la cerámica Local Aconcagua, escasa cerámica Local de fase Inca, ausencia de alfarería diaguita y de otras procedencias, y material lítico que apunta al desarrollo de actividades domésticas en el lugar.

\section{Distrito Pueblo del Maipo o Tablongo}

El 26 de mayo de 1580, las tierras y estancia de Tablongo fueron entregadas en merced por el gobernador Martín Ruiz de Gamboa al castellano Diego Cifontes de Medina,

Diciendo que parase sustentar tenia neecessario de unas tierras y estancia en terminos desta ciudad que sse llaman Tablongo y por otro nombre Gualembonco y que lindan por la parte desta ciudad de Santiago con el Principal de
Alonsso de Cordova llamado Rrengua guanelen y por otra parte el rrio de Maypo y por la otra parte con tierras de los indios de Garcia Hernandez que sson agora de Diego Garcia el Moço y por las cabeçadas la estancia del Ospital de los terminos desta ciudad (RA, vol. 2845, pieza 7).

La localización de las tierras de Tablongo y la existencia de un canal de regadío se conoce a partir de la merced de una chacra de 200 varas de tierra otorgada por el gobernador Martín de Gamboa a Diego de Cáceres el Mozo, el 6 de junio de 1580:

[...] me pidio y suplico que atento a lo suso dicho y que Garcia Hernandez su padre sirvio a su majestad en este reyno le hiciese merced en nombre de su majestad del otro pedazo de tierras por mi visto [...] del dicho pedazo de tierra en la parte donde pide que comiença passado el bado del dicho rrio sobre la mano derecha desde el cerro que llaman de Tablongo y baja el rrio abajo y tenga de cabeçada desde el dicho rrio hacia la acequia que del sale duzcientas baras (RA, vol. 2845, pieza 7). 


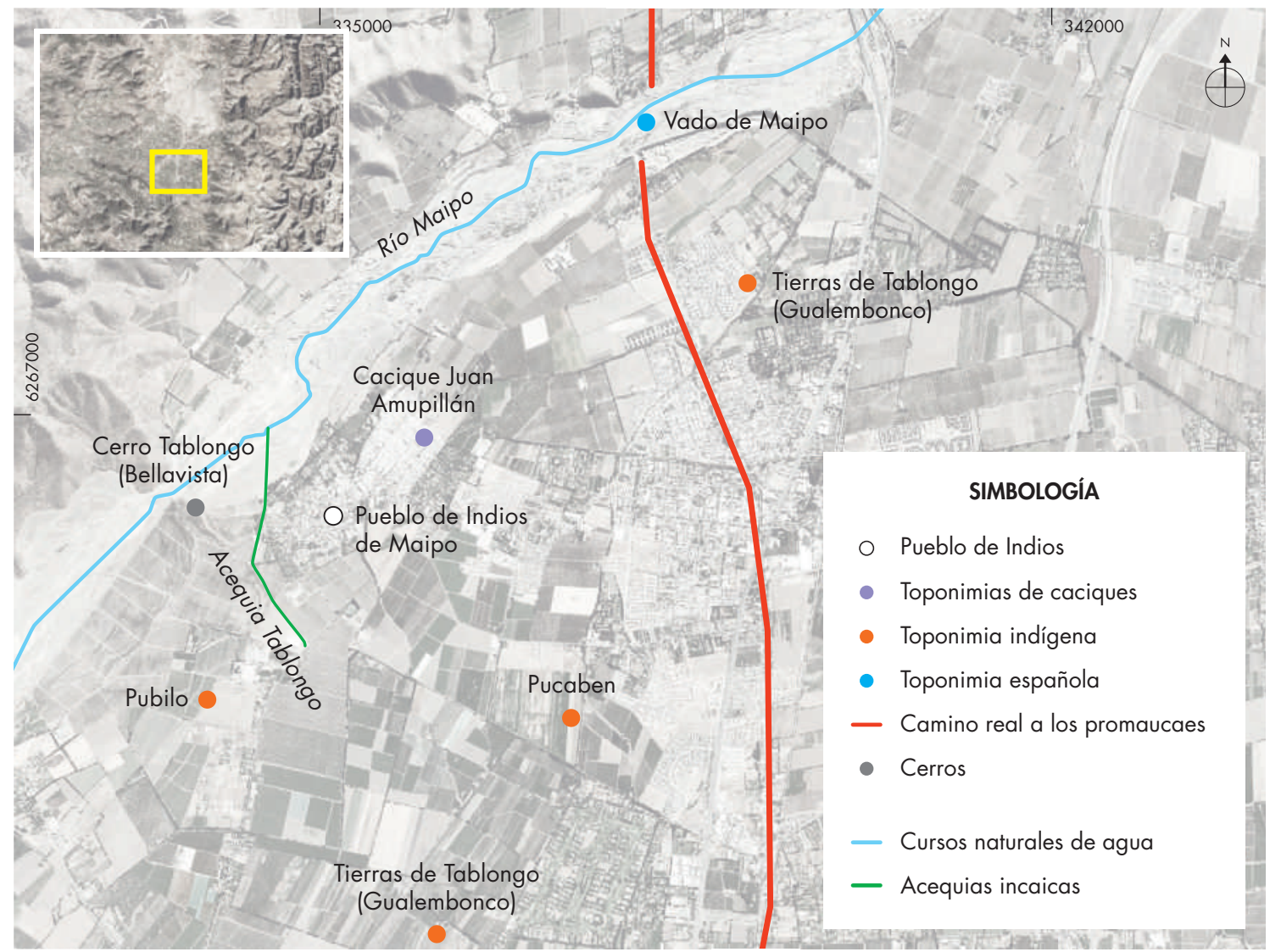

Figura 10. Reconstrucción hipotética del camino real a los promaucaes y localización de los topónimos del distrito Pueblo del Maipo o Tablongo. Figure 10. Hypothetical reconstruction of the Inca royal road to the promaucaes and location of place names of the Tablongo or Pueblo del Maipo district.

Además, se menciona una venta de tierras en ese mismo sector el 27 de abril de 1589, en que el administrador de indios Martín de Zamora autorizó la venta de tierras indígenas de un tamaño de 60 cuadras de largo y 60 cuadras de ancho a Miguel de la Cerda: "[...] abajo del cerro Tablongo, desde donde remata la estancia de Diego de Cáceres, el Mozo" (RA, vol. 2845, pieza 7). El cerrito de Tablongo, denominado hoy Bellavista, se localiza en la ladera sur del río Maipo y adyacente al pueblo del Maipo (fig. 10).

En una escritura de venta de agua de una acequia, el 13 de noviembre de 1593, se indica que el cacique Juan Amopillán del pueblo de Maipo, que es señor de Pubilo, Pucaben y Tablongo de la otra parte del río Maipo y perteneciente a la encomienda de Juan Godínez, vendió el uso del tercio del agua de su "acequia prenzipal" que se encontraba en el Tablongo a Bartolomé del Arco (ES, vol. 10, f. 349). Por una cita anterior, se sabe que la acequia de Tablongo sacó sus aguas del río Maipo. Aunque ninguna referencia señala que esta acequia era vieja o antigua, postulamos que, al igual que la mayoría de las acequias indígenas localizadas al norte de este río, era prehispánica y construida durante el Período Tawantinsuyu (Stehberg et al. 2021). La incluimos en la categoría de tierras asignadas a la comunidad dentro de la división de tierras incaicas. Le otorgan importancia a este distrito la proximidad al "camino real que iba a los promaucaes" o "camino del vado del Maipo" y su asignación al nieto de uno de los principales conquistadores castellanos.

Gaspar Hernández de la Serna y su esposa Ana Félix de Cifontes, quien era hija de Diego de Cifontes de Medina, vendieron una estancia de tierras en el valle de la Angostura, denominada posteriormente Viluco, al presbítero Antonio Fernández Caballero en 1615. Esta estancia lindaba con 


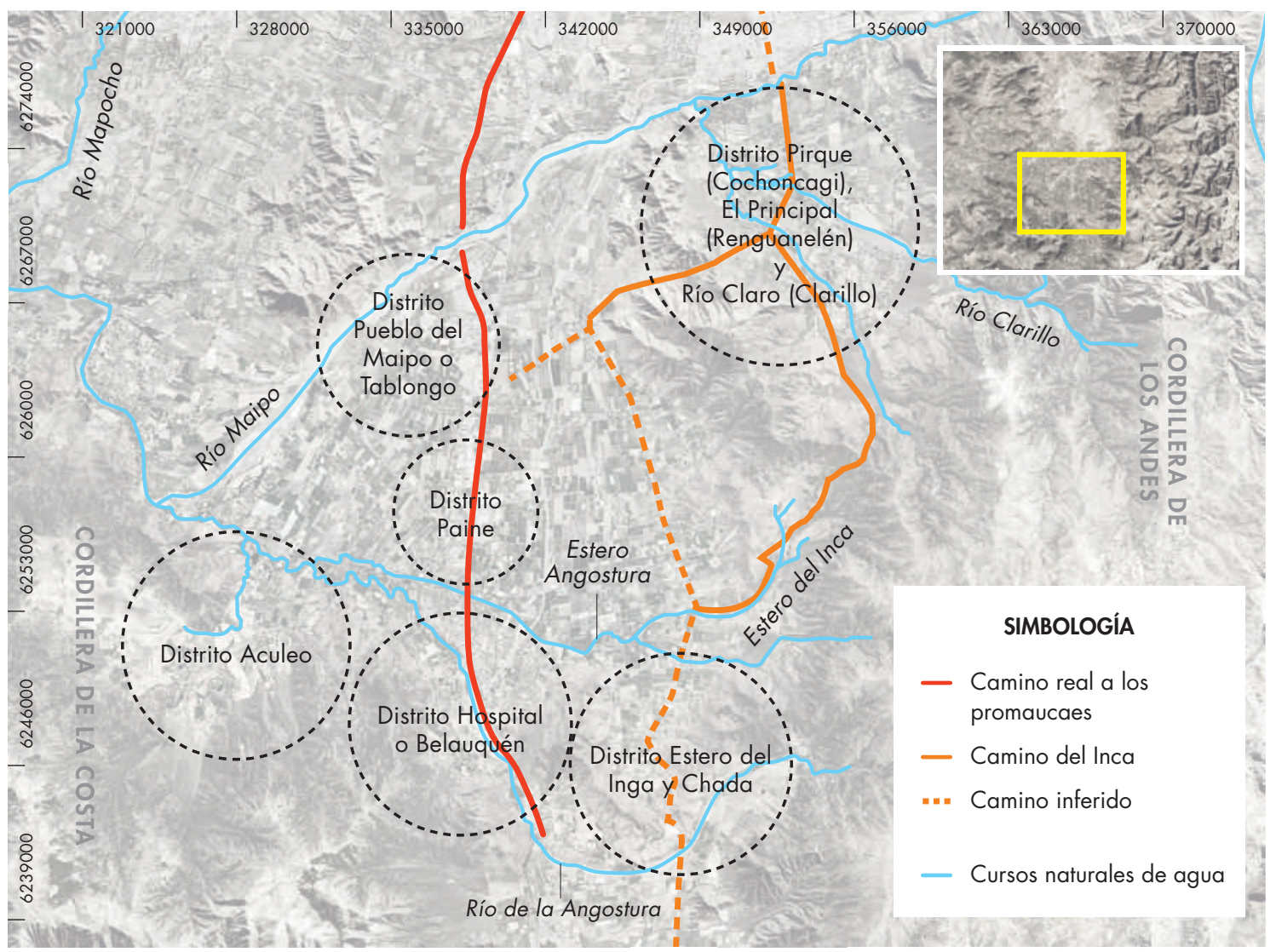

Figura 11. Localización de los seis distritos poblacionales propuestos y su relación con el Camino del Inca y con el camino real a los promaucaes. Figure 11. Location of the six population districts proposed and their relation to the Inca Trail and the Inca royal road to the promaucaes.

[...] tierras de Francisco de León (yerno de Gaspar Hernández), el camino real que ba de esta ciudad a la Angostura de carretas y por la otra parte con tierras de Diego de Caseres y Bartolomé del Arco, en que se incluye un xiron de tierra que al presente tiene y posehe don Melchor cacique de la encomienda de Juan Godínez (ES, vol. 84, f. 6).

Gaspar Hernández declara, además, que esta estancia la había comprado a Juan Godínez de Benavides y su esposa Aldonza Guzmán.

El 5 de agosto de 1575, el gobernador Rodrigo Quiroga otorgó una merced de tierras de 300 cuadras de largo y 150 de ancho a Cristóbal Muñoz: "De la otra banda del rio Maypo desde donde desemboca el rio Claro en el dicho rio Maypo que se llama el cerro que alli esta Caluncura y desde alli el rio abajo hacia tierras baldías" (RA, vol. 2845, pieza 7). Su hijo, el presbítero Bartolomé Muñoz, vendió parte de dichas tierras a Antonio Chacón Morales en 1619: "Un pedazo de tierras en el valle del
Maypo que empiezan en la junta de los ríos de Maipo y Claro y van por la serranía hasta pasar el portezuelo y hasta la tambería del inga" (RA, vol. 2845, pieza 7), en el cordón de cerros Los Ratones, al interior de la actual viña Santa Rita, cerca de Alto Jahuel. Además, vendió en 1623 otro pedazo de tierra que lindaba con la acequia del Hospital hasta el estero de Paine Paine a Juan Bautista Maturano, extendiéndose hasta dos cuadras antes de llegar al cerro Tablongo (ES, vol. 86, f. 198).

\section{DISCUSIÓN Y CONCLUSIONES}

La ocupación Tawantinsuyu al sur del Maipo se habría estructurado en torno a seis distritos poblacionales principales y a dos caminos longitudinales (fig. 11), constituyendo estos últimos la prolongación sur de los caminos del Inca y los senderos indígenas locales exis- 
tentes en el sector norte del valle del Mapocho descritos en un artículo anterior (Sotomayor et al. 2016). Ambas vías tuvieron un origen prehispánico, pero sus historias fueron radicalmente distintas.

Aunque no se dispone de evidencia física del Qhapaq Nan o Camino del Inca al sur del río Maipo, la documentación histórica temprana es bastante precisa para confirmar su existencia. El cronista Vivar relató que Pedro de Valdivia, al poco tiempo de fundar la ciudad de Santiago, recorrió el río Maipo en busca de un lugar apto para construir un puente. En esa exploración visitó un viaducto hecho por los incas, pero lo descartó por no parecerle lugar apropiado, eligiendo otro sector aguas abajo.

Esta pasarela correspondió posiblemente al "puente viexo" del mapa colonial de la figura 1, próximo a la confluencia del río Claro con el Maipo. Su existencia confirmó el paso del Camino del Inca por dicho lugar. Aparentemente, el sendero pasaba al poniente del cerro Las Cabras, en Puente Alto, pero su continuación hacia el centro administrativo y ceremonial incaico del valle del Mapocho (actual Plaza de Armas de Santiago) se desconoce. Posiblemente, el antiguo camino desapareció y no parece coincidir con grandes avenidas actuales como Vicuña Mackenna o Carmen. Tampoco hay que descartar una probable conexión vial con el tambo de Macul, en Peñalolén, y el tambo viejo de Apoquindo, ambos en la falda de la cordillera andina; aunque tampoco existe evidencia de ello.

Del "puente viejo" el camino continuaba rumbo sur hacia el "tambo" de El Principal de Pirque y de allí se bifurcaba atravesando el "ataxo por cassas del Inga" (Odone 1997: 194), en dirección a "jaguei” (Alto Jahuel) y al "portezuelo viejo". Sus continuaciones son especulativas debido a la falta de evidencia arqueológica e histórica. El Estero del Inca y los importantes sitios Tawantinsuyu de Ruinas de Chada y de Cerro Grande de La Compañía, sugieren que el camino del "portezuelo viejo" debió continuar en esa dirección para atravesar luego el cordón de Angostura por el paso de Chada y penetrar al valle de Cachapoal. Existe el gran inconveniente de que un detallado mapa de esa región de 1617 no muestra este camino. Tampoco lo mencionan las primeras mercedes de tierras entregadas en el sector.

Respecto de la otra bifurcación, está indicada en el mapa de 1617 como "camino de caballos", que iba a la Angostura y Aculeo, pero persisten dudas respecto de si ese camino existió antes de la llegada de los españoles.
El "camino real a los Promaucaes", también conocido como "camino real al vado del Maipo", "camino real del pueblo de Rancagua" o simplemente "camino real de carretas", cruzaba la Cañada (actual avenida Alameda) a la altura de la actual avenida Nataniel de la ciudad de Santiago y continuaba por un llano árido rumbo sur hasta el río Maipo, cruzándolo a través de un vado. Recién al acercarse al paso La Angostura de Paine, en el cordón transversal del mismo nombre, el camino circuló por un distrito fuertemente incaizado, con presencia de los "pucaranes del Inga", de edificios de piedra, tambo y de la guaca inga del cerro grande de Tatay. Pensamos que estos últimos elementos no convirtieron esta ruta en un auténtico camino del Inca. A la ausencia de un puente colgante para cruzar el río Maipo, se suma la falta de mención en las fuentes hispanas de las clásicas mejoras viales incaicas y de topónimos quechuas.

Deseamos plantear la hipótesis de que esta ruta prehispánica sirvió a las poblaciones locales desde tiempos inmemoriales para unir las tierras del sur de Chile (Araucanía) con los territorios de más al norte (diaguitas) y centro-oeste argentino. Sería preexistente al Período Tawantinsuyu, pero el Inca la utilizó sin introducir sus clásicas mejoras viales, asignándole el nombre de Purun Auca (en quechua "gente rebelde", "lobos monteses"), denominación que perduró en el Período Temprano bajo el nombre de camino real a los promaucaes.

Con respecto al distrito Pirque, Río Claro y El Principal, la arqueología y la documentación histórica proporcionan interesante información acerca de la prehistoria tardía local. La arqueología ha confirmado la presencia de sitios de ocupación de la cultura Aconcagua, en tiempos inmediatamente anteriores al Período Tawantinsuyu. La toponimia ha conservado el nombre originario de Cochonchachi o Cochoncagi, en el curso inferior del río Clarillo, cercano a la confluencia con el Maipo. Cochoncagi se desglosaría en kó, "el agua"; chón, "estar torcida una cosa sobre sí misma", o choñchoñ, "cierto pájaro grande, nocturno", y cawiñ, "cualquiera fiesta o borrachera que hacen con ocasión del nillatun, de certámenes, etc." (De Augusta 1966). Cagi también podría derivar de la voz cavi o cabi, que alude a una agrupación indígena de un número significativo de familias (Stehberg \& Sotomayor 1999).

La información documental señala al distrito como lugar de residencia de la autoridad principal del valle del Maipo a la llegada de los castellanos, el cacique 
Renguanelén, derivando de este hecho el nombre de El Principal. El lugar contó con un "tambo" y los españoles construyeron allí una iglesia para evangelizar a los nativos. No se han encontrado los restos arqueológicos de esta primera iglesia, pero se supone que se localizó en el mismo lugar donde se encuentra el templo actual. Asimismo, se informó que la tierra estaba "azequiada y surcada de los antiguos" (RA, vol. 214, f. 216v), que las aguas se obtenían del río Claro (Clarillo) y con ellas se regaba el valle y el llano. La ausencia de fortificaciones (pucarás) en el distrito sugirió que, al igual que en otras partes de los valles del Mapocho y del Maipo, la población con cultura Aconcagua se incorporó pacífica y voluntariamente al Tawantinsuyu. En otro artículo (Stehberg et al. 2021) hemos planteado que el carácter pacífico del acuerdo descansó en el interés de la autoridad indígena local de contar con un sistema avanzado de riego que el Inca era capaz de proporcionar, al tiempo que el Tawantinsuyu obtenía el control de la población local y del agua. Aparentemente, algo parecido habría ocurrido en este distrito.

Este sector constituyó una prolongación hacia el lado sur del Maipo de la extensa red de canales que el Tawantinsuyu construyó al lado norte de dicho río y en el valle del Mapocho. La importancia que alcanzó este distrito quedó de manifiesto cuando su gente fue entregada en encomienda a los principales conquistadores castellanos Alonso de Córdoba el Viejo, Rodrigo de Quiroga y Juan de Cuevas, en tanto que las tierras fueron otorgadas en merced a Alonso de Córdoba el Mozo, Francisco Muñoz y Pedro Miranda.

$\mathrm{Al}$ igual que el anterior, el distrito Estero del Inca y Chada contó con los sitios arqueológicos Turbinas 1 y Turbinas 2, que fueron ocupados por la cultura Aconcagua, preexistente a la llegada del Tawantinsuyu (Stehberg et al. 1996; Planella \& Stehberg 1997; Pavlovic et al. 2019). Asimismo, se encontraron las Ruinas de Chada, un complejo ceremonial inca caracterizado por su trazado de alta complejidad arquitectónica y por la existencia de una cavidad ushnu en su pequeña cima.

Por su parte, las fuentes históricas describieron la cueva de guayra vasi de la cual salía viento (casa del viento). Fue tal su importancia que dio nombre a todo el cordón de La Angostura, conocido en el siglo XVI como "serranía de la guaca delinga", topónimo original que debiera rescatarse. En la segunda mitad del siglo XVII, los habitantes del pueblo de indios de Chada aún recordaban el pueblo antiguo con sus ranchos, arboledas y el paraje donde estuvo el tambo. Al visitar Chada en la primera mitad del siglo XVI, el cronista Vivar mencionó que los incas poblaron allí un pueblo, cuyos cimientos estaban arruinados. ¿Se habrá referido a las Ruinas de Chada, al tambo o al pueblo antiguo?

Completa el distrito el sector de Estero del Inga, una rinconada a unos $10 \mathrm{~km}$ al NE de Chada, donde los incas emplazaron un pequeño reducto fortificado de cumbre en el cerro El Peral. Es significativa la ausencia en la documentación histórica temprana de toda mención a canales prehispánicos y a los caciques del distrito. No creemos que sea simplemente una omisión de las fuentes. La ausencia de una autoridad fuerte y la inexistencia de riego avanzado pueden estar indicando una naciente o débil ocupación Tawantinsuyu. Cuando la documentación se refirió a los indígenas antiguos de Chada, los relacionó con arboledas, más cercano al mundo de la recolección que de la agricultura.

Aparentemente, existió una incipiente división estatal de tierras, ya que los indígenas del pueblo de indios de Chada declararon en la segunda mitad del siglo XVII respecto del Estero del Inca "no aver sido las dichas tierras pertenecientes al dicho pueblo" (RA, vol. 857, pieza 1, f. 57r, 1689). Finalmente, lo que distinguió a este distrito de otros situados más al norte fue la extrema sacralización del paisaje, representado por la presencia de una guaca y un adoratorio (Ruinas de Chada) -ambas de rango estatal- y la presencia de un fortín con el claro propósito de asegurar el control de la población local y del importante paso de Chada. Sin embargo, nuestra investigación no logró probar la existencia del Camino del Inca por el sector, el cual quedará como hipótesis de trabajo a la espera de su confirmación.

La ocupación inca del distrito de Hospital (Belauquén) quedó magníficamente descrita en la merced de tierras a Alonso de Miranda y que por su importancia repetimos: "dichas tierras antiguamente llamadas Belauquén y en ellas habían tenido sus tambos”. Abarcaban

[...] desde el serrillo de los pucaranes del inga hasta el rio de la Angostura [...] y de la otra parte del cerro de la Guaca (del agua) delinga [...] cerca del serrillo donde los ingas tuvieron un fuerte y junto donde los ingas en lo mas llano tuvieron edificios de piedra (FHNSS, AD0001).

Se especifica que este cerro estaba a 12 cuadras al norte del paso La Angostura, lo cual nos permitió ubicarlo en el actual cerro Algarrobo, permitiendo el hallazgo de un nuevo sitio inca. No hay que confundir este pucará con el 
del cerro Collipeumo, en Aculeo, del cual quedan algunos vestigios arqueológicos (Medina 1882), pero que hasta la fecha no ha sido mencionado en la documentación hispana. También reviste gran interés la mención, en 1583, a la existencia de un "malar grande de madera de palos" (FHNSS, AD0005) a siete cuadras del paso La Angostura. El mismo pudo corresponder a un fortín o a un corral (malal en mapuzungun) para resguardo del ganado indígena. Dada la poca duración de la madera, suponemos que correspondió a tiempos históricos.

Respecto del distrito de Aculeo, las fuentes históricas tempranas señalan que el sector estuvo bajo dominio incaico y que, incluso, hubo división de la propiedad en tierras que pertenecieron al Inca, las que entregó a la comunidad. Es muy significativo que el cacique Hernando de Aculeo, vendió en 1538 "tierras de su padre y a este se las dio el inga” (FHNSs, AD0005). También se señala que hubo un tambo en Aculeo y este estuvo a media legua de la desembocadura del estero en la laguna de Aculeo. Se menciona una segunda laguna, más pequeña, llamada Pichicauquén. Se nombra el cerro Collupilegmu (Collipeumo), sin especificar qué hubo en su cima.

Al igual que en el distrito Estero del Inca y Chada, ninguna fuente menciona la existencia de grandes canales. Es posible que simplemente no los hubiera y que el sector contara con las pequeñas acequias que construían los horticultores locales. Tampoco se indica el nombre de alguna autoridad destacada. Lo más probable es que el personal que el Tawantinsuyu emplazó en Belauquén, en el pucará del Inca, en los edificios de piedra $y$ en el tambo de Aculeo fuera destinado al control del tráfico de personas y bienes por el "Camino Real a los Promaucaes" y a la vigilancia de sus instalaciones y de la población local. Al igual que en el distrito Estero del Inca y Chada, la estrategia implementada por el Inca fue dual y consistió, por una parte, en el apoderamiento simbólico del cordón de La Angostura de Payne Payne, denominando al cerro más alto Tatay (tata: padre) como "serro Tayay que es el grande de la guaca del inga" (FHNSs, AD0001). Por otra parte, por medio de la construcción de los "pucaranes del inga" se aseguró la defensa militar del paso La Angostura de Paine, para el eventual caso de que la estrategia simbólica fracasara.

Respecto del distrito Paine, la documentación histórica ofrece poca información en relación con la presencia Tawantinsuyu, reducida a que por el sector atravesó el estero Linca, el cual procedía de las montañas adyacentes.
Finalmente, el distrito Pueblo de Maipo (Tablongo), se localizó en el lado sur del río Maipo, cercano al vado del "Camino Real a los Promaucaes". Fue entregado en merced en 1580 a Diego de Cifontes y a Diego de Cáceres el Mozo. Tuvo un canal de regadío. En 1593, el cacique Juan Amupillán del pueblo de indios del Maipo vendió a Juan Gudínez derechos de agua sobre dicha acequia. No se dispone de mayor información sobre este distrito, ni tampoco se pudo saber si el origen del canal fue prehispánico, aunque sería lo más probable.

$\mathrm{El}$ análisis de los distritos poblacionales indígenas permitió distinguir los sectores con mayor o menor presencia inca en el área, siendo el distrito Pirque-El Principal-Río Claro representante de los primeros, en tanto que el distrito Paine correspondió a los segundos, sin participar prácticamente del sistema, quedando el resto en una situación intermedia. Esto significa que el Tawantinsuyu no tuvo una presencia homogénea ni continua en este territorio, escenario que fue común a lo largo del Estado.

Los estudios arqueológicos también han resaltado las diferencias que se advierten entre los valles del Mapocho y del Maipo (Dávila et al. 2018). En este último destaca la presencia de complejos arquitectónicos sobre cerros, con utilización de

[...] arquitectura en piedra a una escala no conocida previamente en la zona, lo que les otorga un grado significativo de monumentalidad. Instauran una preeminencia espacial y territorial de la presencia inca en todas las zonas en que se ubican, ya que se emplazan en forma adyacente a espacios ocupados por las poblaciones locales para desarrollar actividades domésticas [...] en estos conjuntos arquitectónicos se habrían ejecutado de manera prioritaria ritos que permitieron y contextualizaron la relación, la negociación política y administrativa entre las comunidades locales y el Tawantinsuyu. Estos eventos habrían sido de distinto tenor: festividades y amplias convocatorias en el cerro Chena, grupos acotados y actividades más especializadas en Ruinas de Chada y posiblemente también en Collipeumo (Pavlovic et al. 2019: 71-72).

Creemos que nuestro trabajo interdisciplinario proporcionó resultados novedosos y de calidad para el área de estudio. La integración de la evidencia arqueológica con la información documental histórica y la perspectiva geográfico/cartográfica utilizada permitieron una visión holística y sinérgica del estado de desarrollo cultural, político, social y económico en que se encontraba el valle del Mapocho/Maipo al momento de la irrupción de los castellanos al área, ayudando de paso a entender por qué 
se asentaron en forma definitiva en este territorio. Con este artículo concluyó la ambiciosa meta que Gonzalo Sotomayor (q. e. p. d.) y el primer autor de este artículo se propusieron en el año 2011.

Recapitulando, la ocupación Tawantinsuyu al sur del Maipo se caracterizó por una disminución drástica de la hidroagricultura, la cual se redujo al distrito Pirque, El Principal y Río Claro y al distrito Pueblo del Maipo (Tablongo). Más al sur, en los distritos colindantes al cordón de Angostura de Paine, la agricultura de riego avanzado incaico no estuvo presente. Las construcciones arquitectónicas en cerros estuvieron directamente relacionadas con las dos vías de circulación longitudinal, una de las cuales correspondió al Qhapaq Ñan (camino principal Inca), en el sector oriente cercano a la cordillera andina y la otra, a un antiguo camino indígena local, en el sector central del valle, que fue reutilizado durante los períodos Tawantinsuyu y Colonial. Su función fue, por una parte, brindar protección y control al tráfico de personas y bienes por dichos portezuelos y proteger la infraestructura incaica, y por otra, servir como lugar de congregación social para establecer negociaciones con la población local. Para lograrlo el Estado inca construyó las instalaciones de El Peral, Collipeumo y los Pucaranes del Inga y estimuló la sacralización del paisaje mediante el establecimiento de guacas principales (guayra vasi, cerro Tayay) y la construcción de las Ruinas de Chada.

\section{NOTAS}

${ }^{1}$ Denominación establecida por los arqueólogos debido a que los primeros hallazgos fueron realizados en el valle de Aconcagua.

${ }^{2}$ Sobre el fin de la cultura Aconcagua y su relación con el Tawantinsuyu, véase Sánchez (2001).

${ }^{3}$ Pleito del 6 de marzo de 1561 "contra Juan Gómez y otros sobre la posesión de los repartimientos de indios del valle de Quillota y Mapochoes" (Medina 1897: 366).

${ }^{4}$ También existió, con posterioridad, un camino real denominado del Puente Nuevo, el que siguió una ruta similar al anterior, pero que cruzaba el río Maipo poco más abajo de la desembocadura del río Claro. Se correspondía aproximadamente con la actual avenida Santa Rosa.

${ }^{5}$ En la toma de posesión se indica que "[...] le señalé la distancia de las dichas tierras y mojones que corren 150 cuadras desde el tambo [...] y por mojón la questa del camino real que va a lo del hospital desta ciudad de Santiago" (Izquierdo 1982: 228).

\section{REFERENCIAS}

Actas del Cabildo de Santiago (1541-1557) 1861. En Colección de historiadores de Chile y de documentos relativos a la historia nacional, tomo I, pp. 63-622. Santiago: Imprenta del Ferrocarril. <http://www.memoriachilena.gob.cl/602/ w3-article-8904.html> [consultado: 29-10-2021].

ANH, ES. Archivo Nacional Histórico (Santiago de Chile), Escribanos de Santiago, vols. 9, 10, 47, 56, 73, 84, 86, 144, 258.

ANH, Fv. Archivo Nacional Histórico (Santiago de Chile), Fondos Varios, vol. 270.

ANH, MI. Archivo Nacional Histórico (Santiago de Chile), Ministerio del Interior, vol. 208. Croquis de los dos caminos entre Santiago y Rancagua / J. Álvarez Condarco [material cartográfico].

ANH, RA. Archivo Nacional Histórico (Santiago de Chile), Real Audiencia, vols. 214, 409, 857, 2845, 2878, 2881.

ARNAD, Ns. Archivo Nacional de la Administración (Santiago de Chile), Notarios de Santiago. Escrituras de hipotecas 1792-1858, tomo 1.

Berenguer, J., I. Cáceres, C. Sanhueza \& P. Hernández 2005. El Qhapaqñan en el Alto Loa, Región de Antofagasta: un estudio micro y macromorfológico. Estudios Atacameños 29: 7-39.

Cabeza, Á. \& P. Tudela 1985. Reseña histórica y cultural de Pirque y Río Clarillo. Santiago: ConAf-Ilustre Municipalidad de Pirque.

Colección de historiadores de Chile y documentos Relativos a LA Historia NACIONAL 1861. Cartas de Pedro de Valdivia al emperador Carlos $V$ y primer libro de Actas del Cabildo de Santiago (1541-1557). Tomo I, p. 126. Santiago: Imprenta del Ferrocarril. <http://www. memoriachilena.gob.cl/602/w3-article-8904.html> [consultado: 29-10-2021].

Сово, В. 1890-1893 [1653]. Historia del Nuevo Mundo. Colección de libros y documentos referentes a la historia de América, 4 vols. Sevilla: Imprenta de E. Rasco.

Dávila, C., C. Cortés, A. Martínez, J. Hermosilla, N. Fuenzalida \& D. Pavlovic 2018. Interacción social al sur del Kollasuyu. Alfarería funeraria del Período Tardío (1400-1536 DC) en la cuenca Maipo-Mapocho. Chungara 50 (4): 577-590.

De augusta, Fray F. J. 1966. Diccionario Araucano. Tomo primero Araucano-Español. Padre Las Casas: Imprenta y Editorial San Francisco.

Falabella, F., D. Pavlovic, M. T. Planella \& L. Sanhueza 2016. Diversidad y heterogeneidad cultural y social en Chile Central durante los períodos Alfarero Temprano e Intermedio Tardío (300 años AC a 1450 años DC). En Prehistoria en Chile. Desde sus primeros habitantes hasta los Incas, F. Falabella, M. Uribe, L. Sanhueza, C. Aldunate \& J. Hidalgo, eds., pp. 365-399. Santiago: Editorial Universitaria-Sociedad Chilena de Arqueología. 
Gómez, A., C. Prado \& F. Ocaranza 2014. Asientos indígenas en la precordillera de Santiago (siglos xvi y XVII). Estudio de caso. Revista de Historia y Geografía 30: 57-84. <https://doi. rg/10.29344/07194145.30.387> [consultado: 31-07-2021].

GonzÁlez, C. 2017. Arqueología vial del Qhapaq Ñan en Sudamérica: análisis teórico, conceptos y definiciones. Boletín del Museo Chileno de Arte Precolombino 22 (1): 15-34.

Hyslop, J. 1984. The inka road system. Orlando: Academic Press. Instituto Geográfico Militar 1981. Atlas cartográfico del Reino de Chile. Siglos XVII-XIX. Santiago: IGM.

IzQuiERDo, C. 1982. La tenencia de las tierras entre los ríos Clarillo y Maipo desde 1542 hasta 1700. Santiago: Instituto de Historia, Pontificia Universidad Católica de Chile.

JARA, A. 1961. El salario de los indios y los sesmos de oro en la Tasa de Santillán. Santiago: Universidad de Chile.

LA Mura, N. \& R. SÁNCHEZ 2016. Configuración arquitectónica y uso del espacio en el extremo austral del Tawantinsuyu: nuevas perspectivas en torno al "Pucará de Chena". En Actas del XIX Congreso Nacional de Arqueología Argentina, Facultad de Ciencias Naturales e Instituto Miguel Lillo, eds., Serie Monográfica y Didáctica, vol. 54, pp. 1897-1901. San Miguel de Tucumán: Universidad Nacional de Tucumán.

LEón, L. 2017 Ms. La conformación de la propiedad europea en la cuenca de Santiago, siglo Xvi. Copia en poder de los autores.

Medina, J. T. 1882. Los aborígenes de Chile. Santiago: Gutenberg. Medina, J. T. 1897. Colección de documentos inéditos para la historia de Chile. Tomo xI. Santiago: Imprenta Elzeviriana.

MNM, FHNss. Museo Nacional de Medicina (Santiago de Chile), Fondo Hospital Nuestra Señora del Socorro, ad. 0001, 0005.

OdOnE, C. 1997. El valle de Chada: la construcción colonial de un espacio indígena de Chile central. Revista de Historia 30: 189-209.

Olivares, M. DE 1864. Historia militar, civil y sagrada de Chile. En Colección de Historiadores de Chile y documentos relativos a la historia nacional, tomo Iv. Santiago: Imprenta del Ferrocarril.

Pavlovic, D., R. Sánchez, D. Pascual, A. Martínez, C. Cortés \& N. La Mura 2019. Rituales de la vida y la muerte: dinámicas de interacción entre el Tawantinsuyu y las poblaciones locales en la cuenca del Maipo-Mapocho, Chile central. Estudios Atacameños 63: 43-80.

Planella, M. T. \& R. Stehberg 1997. Intervención inka en un territorio de la cultura local Aconcagua de la zona centro-sur de Chile. Tawantinsuyu 3: 58-78.

Real Academia Española 2019. Diccionario de la lengua española. 23. a edición, versión 23.4 en línea. <https://dle. rae.es> [consultado: 10-08-2021].

Ruano, N. 2012. Arqueoastronomía inca en el sitio Ruinas de Chada. Región Metropolitana, Chile. En Actas del XIX Congreso Nacional de Arqueología Chilena, R. Ajata, D. Munita, R. Moyano, I. Leibowicz, I. Muñoz, M. Uribe, P. González, J. Tamblay, I. Cáceres, L. Núñez, G. Carmona, F. Vilches, J. Sauer, R. Mera, V. Standen, S. Urbina, G.
Cabello, D. Jackson, I. Correa, A. Martínez, F. Mena, R. Campbell, A. Oyaneder, D. Jofre \& M. Corvalán, eds., pp. 133-140. Arica: Universidad de Tarapacá-Sociedad Chilena de Arqueología.

SÁNCHEZ, R. 2001. El fin de la Cultura Aconcagua y su relación con el Tawantinsuyu. En Actas del IV Congreso Chileno de Antropología, A. Aravena, M. Castro, R. Sepúlveda \& M. Weisner, eds., pp. 1432-1437. Santiago: Colegio de Antropólogos de Chile A. G. <https://www.aacademica. org/iv.congreso.chileno.de.antropologia/206.pdf> [consultado: 01-08-2021].

Sanhueza, L., L. Cornejo \& F. Falabella 2007. Patrones de asentamiento en el Período Alfarero Temprano de Chile central. Chungara 39 (1): 103-115.

Silva, E., C. Silva, N. La Mura, N. Fuenzalida \& A. Brinck 2017. Sentidos del patrimonio de los sitios arqueológicos Ruinas de Chada y Pucará de Chena (río Maipo, Chile central: historia local y entorno social). Intersecciones en Antropología 18 (2): 169-179.

Sotomayor, G., R. Stehberg \& J. C. Cerda 2016. Mapocho incaico norte. Boletín del Museo Nacional de Historia Natural 65: 109-135.

Stehberg, R. 1976. La fortaleza de Chena y su relación con la ocupación incaica de Chile Central. Publicación ocasional del Museo Nacional de Historia Natural 23: 3-37. Santiago: Museo Nacional de Historia Natural. <https:// publicaciones.mnhn.gob.cl/668/articles-71078_archivo_01. pdf $>$ [consultado: 01-08-2021].

Stehberg, R. 2013. Caminos, guacas y el reducto fortificado de cerro El Peral: instalaciones para el control inca del paso de Chada, Chile central. Boletín del Museo Nacional de Historia Natural 62: 129-146.

StehberG, R. \& G. Sotomayor 1999. Cabis, guacas-fortalezas y el control incaico del valle de Aconcagua. Estudios Atacameños 18: 237-248.

Stehberg, R., M. T. Planella \& H. Niemeyer 1996. ¿ Grupos diaguitas incaicos controlando una población Aconcagua en el sector de Chada al sur del río Maipo? Actas del XI Congreso Nacional de Arqueología Argentina, Museo Municipal de Historia Natural de San Rafael, ed. (s. pp.). San Rafael: Museo Municipal de Historia Natural de San Rafael.

Stehberg, R., M. T. Planella \& H. Niemeyer 1997. Complejidad arquitectónica de las ruinas prehispánicas de Chada en la antigua ruta entre los ríos Maipo y Cachapoal. Xama 6-11: 53-64.

Stehberg, R. \& G. Sotomayor 2012. Mapocho incaico. Boletín del Museo Nacional de Historia Natural 61: 85-149. <https:// publicaciones.mnhn.gob.cl/668/articles-70584_archivo_01. pdf $>$ [consultado: 01-08-2021].

Stehberg, R., G. Osorio \& J. C. Cerda 2021. Mapocho incaico central: distritos prehispánicos de irrigación. Publicación ocasional del Museo Nacional de Historia Natural 71: 5-60.

VIVAR, G. DE 1979 [1558]. Crónica y relación copiosa y verdadera de los Reinos de Chile. Berlín: Colloquium Verlag. 